\title{
Suspended sediment transport and beach dynamics induced by monochromatic conditions, long waves and wave groups.
}

\author{
Cáceres, I. ${ }^{1}$ and Alsina, J.M. ${ }^{2}$ \\ ${ }^{1}$ Laboratori d'Enginyeria Marítima, Universitat Politècnica de Catalunya, Barcelona, Spain. i.caceres@upc.edu \\ ${ }^{2}$ Fluid Mechanics Section, Department of Civil and Environmental Engineering, Imperial College London, London, \\ UK.j.alsina@imperial.ac.uk
}

\begin{abstract}
This study presents the analysis of the water surface elevation, velocity and suspended sediment concentration measurements obtained at a large wave flume under mobile bed conditions. The wave reproduced Erosive and Accretive conditions, and included Monochromatic, short waves perturbed with a free long wave, Bichromatic and Random conditions. Each tested condition started from a handmade 1/15 slope and lasted for an approximate time period of 2.4 hours (6 runs of the selected wave condition), to compare the different beach profile developments and, in particular, the events that control sediment transport in the swash and surf zones. All Erosive tested conditions produced a shoreline retreat and a bar at the breaking area whose development in time is directly correlated to the length of the breaking area. On the other hand, not all Accretive conditions present a shoreward transport, and random conditions do not seem to alter the initial profile. The processed data show the suspended sediment event control produced by the existence or absence of wave-backwash interactions in the swash zone. The existence of these interactions, and their number within the wave group, will be a key parameter in controlling the sediment stirring, water velocity magnitudes and, therefore, the suspended sediment fluxes in the inner surf and outer swash.
\end{abstract}

Keywords: Sediment transport, swash zone, surf zone, large-scale wave flume, wave-backwash interactions, berm. 


\section{Introduction}

The swash zone is that part of a beach that is alternately covered and exposed by up-rush and backwash, including from the point of bore collapse on the beach face up to the maximum up-rush limit. The swash zone is the link between the emerged beachface and the surf zone (Hughes et al, 1997; Alsina et al. 2012). The relevance of the swash zone is mainly due to the fact that a significant part of sediment transport (cross-shore and longshore) occurs in this area. But it is also important due to the control that the swash exerts over the sediment transport in that area, determining whether the sediment will be stored on the upper beach in the form of a berm or will move to the surf zone.

The berm and bar are the main morphological features to be found in a beach profile. While a great deal of effort has been put in the study of the bar evolution, the berm has received less attention. The berm formation processes has been previously studied considering the effects of wave height, tidal fluctuations, water level changes induced by storms, sediment fall velocity, grain size or permeability (Bagnold 1940, Hine 1979, Weir et al. 2006 or Jensen et al. 2009). But most of the studies dealing with berm formation, are qualitative studies, based on field experimental data highly affected by the tidal effect on gravel beaches. There are very few studies of berm development at intra-tidal time scale, and there is a lack of data linking the morphological and hydrodynamic measurements around the berm formation (Weir et al. 2006).

Butt and Russell (2000), Elfrink and Baldock (2002), Masselink and Puleo (2006), Bakhtyar et al. (2009) have described in their review papers the different forcing terms for the flow and sediment transport in the inner-surf and swash zone. In the last twenty years there has been a significant increase in the number of studies on the swash zone. Nowadays, there are different studies that deal with the terms that play a role in the dynamic at the swash zone: bore collapsing (Puleo et al. 2000, Jackson et al. 2004; Aagard and Hughes 2006), backwash (Horn and Mason 1994 or Butt and Russell 1999), advection (Jackson et al. 2004 or Alsina et al. 2009), infiltration/ex-filtration effects (Turner and Nielsen 1997, Elfrink and Baldock 2002; Baldock and Nielsen 2010), asymmetries in velocity or acceleration (Roelvink and Stive 1989, Mariño-Tapia et al. 2007, Houser and Barret, 2010; Pedrozo-Acuña et al. 2011), long wave and wave groups (Baldock et al. 2011), etc.

The run-up and run-down movement in the beach face can be composed of a pure uprush or backwash movement (pure swash events) or of subsequent swash waves interacting. While the pure swash events have been widely studied (Hughes et al. 1997, Masselink et al. 2009; Blenkinsopp et al. 2011) and even numerically modelled (Hughes and Baldock 2004 or Zhu and Dodd 2013), the 
highly turbulent interaction between consecutive swash events lacks a proper characterization of the phenomena. Several authors have stated that the presence or absence of this interaction may determine the net direction of sediment transport and its profile change (Kemp 1975 or Holland and Pulleo 2001). Hughes and Moseley (2007) gave enough importance to the role of the interaction to divide the swash area into outer and inner swash sub-regions, according to the existence or absence of interactions in each sub-area. The outer swash is the region where wave-swash interaction occurs, while the inner swash is defined as the region where wave-swash interactions are entirely absent (only pure swash events without any interactions with previous or further swash events). Brocchini and Baldock (2008) presented the parameter $\breve{\mathrm{T}}=\mathrm{T}_{\mathrm{s}} / \mathrm{T}$ to quantify the degree of waveswash interaction, where $T$ is the incident wave period and $T_{s}$ the natural swash period. Values of $\breve{T}$ greater than or equal to 1 are associated with a large number of interactions occurring in the swash zone.

Three different kinds of wave-swash interactions have been previously described: wave capture or catch-up, weak wave-backswash interaction, and strong wave-backwash interaction (Erikson et al. 2005, Hughes and Moseley 2007 and Cáceres and Alsina 2012). The wave capture interaction occurs when a second wave captures the previous one during both up-rush stages. The weak wavebackwash interaction occurs when an incoming wave advances across the front of an existing swash lens as it recedes down the beach as backwash. The receding backwash has a limited amount of energy and the incoming up-rush overrun results in an onshore flow. Finally, the strong wavebackwash interaction occurs when the backwash is stronger than the incoming up-rush, resulting in a stationary bore that has been compared to a hydraulic jump by several authors (Puleo et al., 2000; Elfrink and Baldock, 2002; Hughes and Moseley, 2007). The resulting flow, once the up-rush has lost all of its energy in the bore momentum exchange, is offshore directed.

Based on the physics of the events described above and previous data analysis (Alsina and Cáceres 2011 and Cáceres and Alsina 2012), strong wave-backwash interactions and backwash events tend to induce erosion, while incident wave/bore events, wave capture events and weak wave-backwash interactions tend to produce accretion.

The data analysis performed throughout this paper aims to gain a better knowledge of the wavebackwash interactions and pure swash events under monochromatic, combination, bichromatic and random Erosive and Accretive conditions. The paper also focus on the bar and berm formations along the beach profile during the tested conditions. Section 2 deals with the Experimental description. Section 3 presents the results of the bottom evolution profiles, spectral analysis and 
direct analysis of water surface elevation, velocity and suspended sediment concentration. Section 4 discusses the observed data and, finally, section 5 sets out the conclusions of this study.

\section{Experiment Description}

The data set out in this study were obtained in the Swash zone response Under grouping Storm COnditions (SUSCO) project. The SUSCO data set was obtained at the Canal d'Investigació i Experimentació Marítima (CIEM) at the Universitat Politècnica de Catalunya (UPC), Barcelona. It is a large-scale wave flume of $100 \mathrm{~m}$ in length, $3 \mathrm{~m}$ in width and $4.5 \mathrm{~m}$ in depth. The beach commenced $43 \mathrm{~m}$ from the wavemaker, with the toe of the beach at an elevation of $-2.5 \mathrm{~m}$ relative to the SWL and approximately $45 \mathrm{~m}$ seaward of the shoreline. The beach consisted of commercial well-sorted sand with a medium sediment size $\left(\mathrm{d}_{50}\right)$ of $0.25 \mathrm{~mm}$, with a narrow grain size distribution $\left(\mathrm{d}_{10}=0.154 \mathrm{~mm}\right.$ and $\left.\mathrm{d}_{90}=0.372 \mathrm{~mm}\right)$ and a measured settling velocity $\left(\mathrm{w}_{\mathrm{s}}\right)$ of 0.034 $\mathrm{m} / \mathrm{s}$.

The equipment distribution is presented in Figure 1 and Table 1, where the x-coordinate origin is at the initial shoreline with a still water level of $2.5 \mathrm{~m}$, negative towards the wave paddle (offshore) and positive towards the beach face (onshore). The wave height was measured by means of resistive wave gauges in the deeper part of the flume (hereinafter WG), pore pressure sensors (PPTs) in the surf zone and acoustic displacement sensors (ADSs) in the swash zone. The three different devices used for recording the water surface elevation were selected based on previous experiments in the flume, in order to obtain the best possible measurement at each deployment location. The velocity field was mapped by means of acoustic Doppler velocimeters (ADVs), while optical backscatter sensors (OBSs) were used to recover the Suspended Sediment Concentration (SSC).

The SUSCO wave conditions were selected in order to study the influence of long waves, bichromatic wave groups and random waves on the sediment transport measured in the surf and swash zone (Table 2 shows the targeted wave conditions). The dimensionless sediment fall velocity number $\Omega=\mathrm{H}_{\mathrm{b}} / \mathrm{w}_{\mathrm{s}} \mathrm{T}$ (commonly known as the "Dean number", popularized by Dean in 1973 and 1985) was used to forecast the character (Erosive or Accretive) of the waves to be tested. In this paper, 13 different wave conditions will be studied, six Erosive conditions with an averaged $\Omega$ of 3.4, and seven Accretive conditions with an averaged $\Omega$ of 1.4. All wave conditions, Erosive and Accretive separately, had comparable energy content with the exception of the M_A (Monochromatic Accretive) case, which, due to a communication error, had a smaller wave height than that corresponding to the energy content of the other accretive wave conditions. 


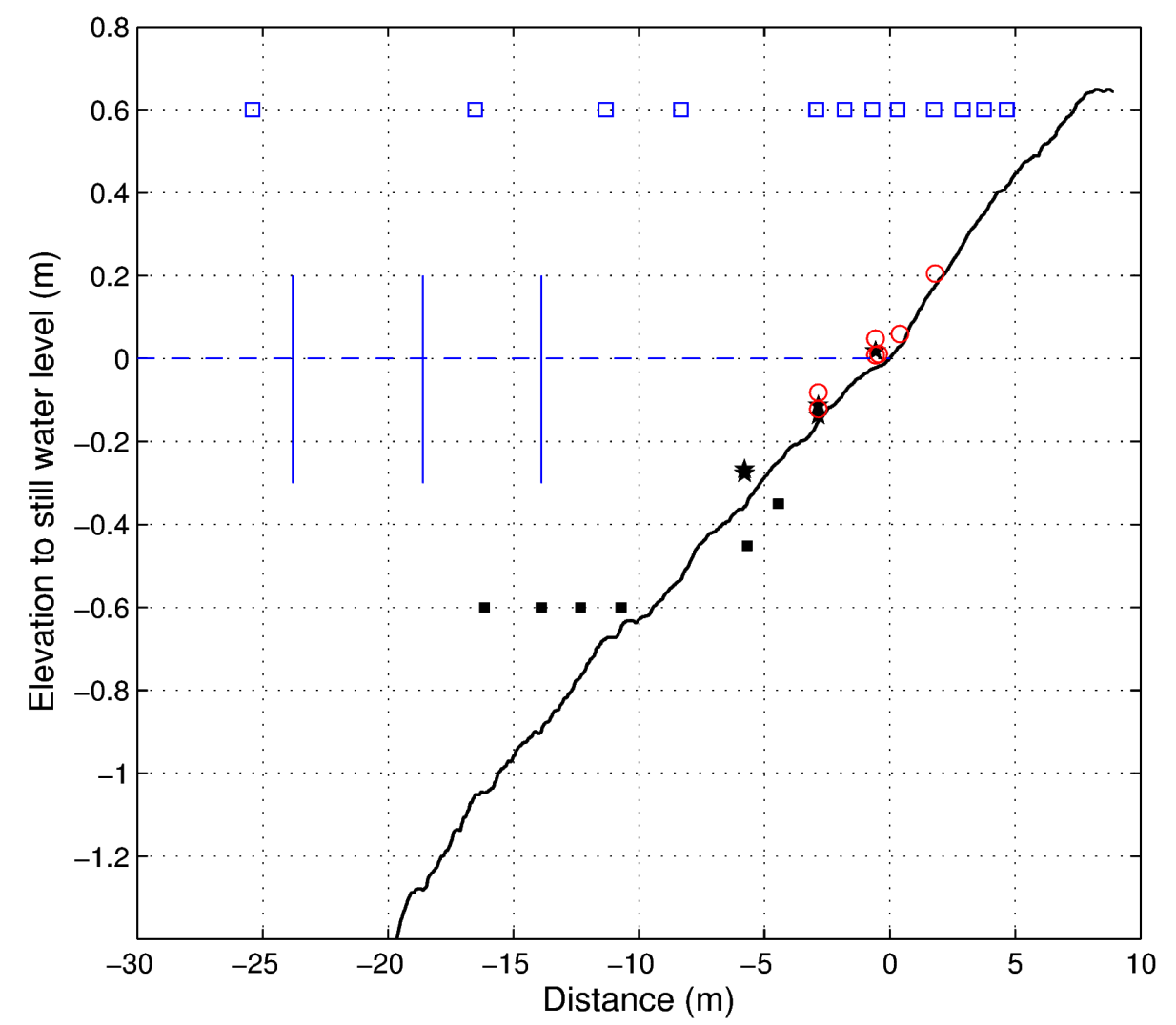

Figure 1. CIEM configuration for the SUSCO experiments. A standard 1/15 initial profile is plotted with a solid black line. The marks show the position for WG (solid blue lines), PPT (solid black squares), ADS (empty blue squares), ADV (solid black pentagram) and OBS (empty red circles).

The waves tested during this project covered monochromatic conditions, a combination of monochromatic short waves plus free long waves, bi-chromatic waves including bound long waves and random waves with different Grouping Factors (GF). Figure 2 shows the various characteristics of the Erosive wave conditions tested during the SUSCO experiments. The left panels show the water surface elevation over a time span of $200 \mathrm{~s}$, while the right panels show the power spectral density function of each of the tested conditions. All measurements shown in Figure 2 were acquired in the flat part of the profile, seaward of the beach toe $(x=-65.3 \mathrm{~m})$. The top panel shows the Monochromatic wave condition (M_E following Table 2 notation), being the computed water surface spectrum controlled by the unique peak of the targeted waves. The second panel from the top is for a combination of waves (C_E4), a small amplitude $(0.04 \mathrm{~m})$ long wave (15 s) was added to the monochromatic signal in order to generate a long wave short-wave combination (the peak of the targeted long wave, $0.065 \mathrm{~Hz}$, is small and not noticeable on the figure scale). The third and fourth panels from the top show both Bichromatic wave tested conditions (B_E1 and B_E2 respectively). The first one with closer frequencies (B_E1), where the targeted component periods were 3.5 and $3.9 \mathrm{~s}$, producing a wave group period of $34 \mathrm{~s}$. The second Bichromatic condition had 
targeted periods of 4.2 and $3.3 \mathrm{~s}$ for each component (B_E2), resulting in a wave group period of 15 s. The wave group spectral energy is very small at the offshore location when compared to the energy of both short wave spectral components. The wave group period for bichromatic conditions can be computed from the frequencies of both short wave components $(f g=f 1-f 2)$. Finally, the last two panels show the two kinds of Random conditions generated with different groupiness factors. The standard approach of wave generation is to use random uncorrelated phases, Grouping Factor of 1. By correlating the phases, higher GF values can be obtained. In this paper the different Random conditions are used mainly as benchmark conditions to compare the various bottom profile evolutions. No other analysis is performed with random conditions and, therefore, no further analysis on the groupiness technique is presented here.

\begin{tabular}{|l|l|}
\hline & cross-shore position (distance from the bottom) \\
\hline WG & $-69.28,-68.28,-67.28,-66.29,-65.29,-55.4,-33.57,-23.7,-18.8$ and $-13.8 \mathrm{~m}$ \\
\hline PPT & $-16.06,-13.8,-12.23,-10.62,-5.59$ and $-4.34 \mathrm{~m}$ \\
\hline ADS & $-2.84,-1.7,-0.6,0.42,1.86,3.0,3.85$ and $4.77 \mathrm{~m}$ \\
\hline ADV & $-5.69(0.09,0.09),-2.75(0.015,0.04)$ and $-0.47(0.04,0.04) \mathrm{m}$ \\
\hline OBS & $-2.75(0.03,0.07),-0.47(0.03,0.07), 0.5(0.03)$ and $1.91(0.03) \mathrm{m}$ \\
\hline
\end{tabular}

Table 1. Equipment distribution along the surf and swash zone during the SUSCO experiments for Erosive conditions. In black the cross-shore position of the gear and in grey the distance to the sandy bottom.
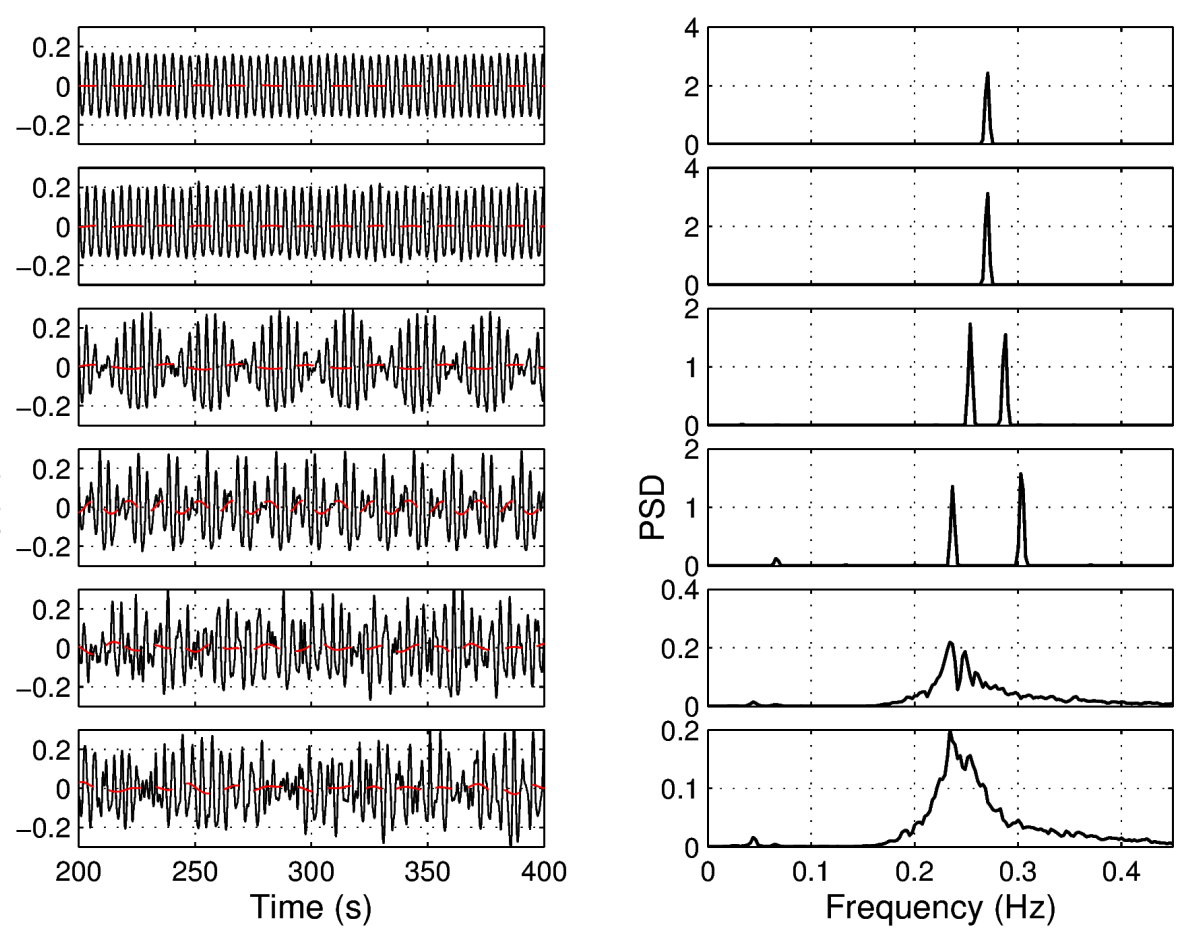

Figure 2. The left panels show the water surface elevation (black) and the computed long wave (dashed red) over 200 seconds, while the right panels show the power spectral density of the complete time series. From top to bottom each row shows the time series and PSD of the SUSCO tested Erosive wave conditions: Monochromatic (M_E), Combination (C_E4), Bichromatic (B_E1 and B_E2) and both Random (R_E1 and R_E2). 
All tests started from a similar initial 1/15 handmade slope. For the erosive conditions the reshaping took place along the active profile, while the reshaping occurred from the landward edge of the bar trough to the run-up limit on the Accretive conditions. The tests were composed of four steps which included five bottom profiles (Figure 3). Each time series lasted 24 minutes and every time series or run was repeated 6 times. The final profile (P4) was generated after a total active wave time of 144 minutes (6 runs of the same time series).

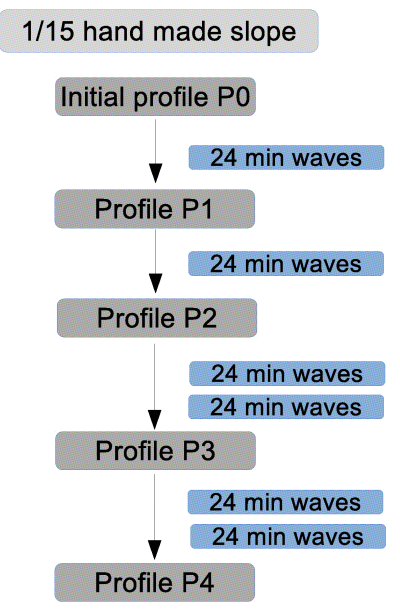

Figure 3. Experimental scheme during the SUSCO project.

Different bottom profiles where acquired during each wave tested condition. One at the beginning of the experiments $(\mathrm{P} 0)$, and consecutively at the end of the $1^{\text {st }}(\mathrm{P} 1), 2^{\text {nd }}(\mathrm{P} 2), 4^{\text {th }}(\mathrm{P} 3)$ and $6^{\text {th }}(\mathrm{P} 4)$ run for each of the 13 wave conditions.

The bottom profile information was acquired by means of a mechanical bed profiler that measures the emerged and submerged profile along a central line of the flume. The mechanical profiler consists of a wheel of $0.2 \mathrm{~m}$ in diameter on a pivoting arm of $3 \mathrm{~m}$ in length, which is mounted on a platform that moves at a constant velocity $(0.10 \mathrm{~m} / \mathrm{s})$ above the flume. The computer that controls the platform velocity converts the arm rotation, and hence the wheel position, into absolute $\mathrm{X}$ and $\mathrm{Z}$ flume bathymetry. The standard deviation of the mechanical profiler over a fixed bed has a mean value of $1 \mathrm{~mm}$. The standard deviation of the mechanical profiler measurement over the sandy bottom has a mean value of $4 \mathrm{~mm}$. This increase in the standard deviation on movable bed bottoms is attributable to three causes: repetition of the wheel path always over the same line, the buoyancy change of the mechanical profiler under a bathymetry change (mainly at the bar features), and the different sand compaction along the profile. 


\begin{tabular}{|c|c|c|c|c|c|}
\hline \multicolumn{6}{|c|}{ Erosive Conditions } \\
\hline \multirow{2}{*}{ Test case } & Short/Primary & Long/Secondar & \multicolumn{3}{|c|}{ Wave type } \\
\hline & $\begin{array}{c}\text { Wave } \\
\text { H (m) }\end{array}$ & $\begin{array}{c}\text { y Wave } \\
\mathrm{T}(\mathrm{s})\end{array}$ & $\mathrm{H}(\mathrm{m})$ & \multicolumn{2}{|l|}{$\mathrm{T}(\mathrm{s})$} \\
\hline M_E & 0.37 & 3.7 & & & Monochromatic \\
\hline C_E $\bar{E} 4$ & 0.37 & 3.7 & 0.04 & 15 & Combination \\
\hline B E1 & 0.26 & 3.9 & 0.26 & 3.5 & Bi-chromatic \\
\hline B_E2 & 0.26 & 4.2 & 0.26 & 3.3 & Bi-chromatic \\
\hline R_E1 & 0.53 & 4.1 & & & Random GF=1 \\
\hline $\mathrm{R}$ E2 & 0.53 & 4.1 & & & Random GF=1.1 \\
\hline \multicolumn{6}{|c|}{ Accretive Conditions } \\
\hline \multirow{3}{*}{ Test case } & Short/Primary & Long/Secondar & \multirow{2}{*}{\multicolumn{3}{|c|}{ Wave type }} \\
\hline & wave & y Wave & & & \\
\hline & $\mathrm{H}(\mathrm{m})$ & $\mathrm{T}(\mathrm{s})$ & $\mathrm{H}(\mathrm{m})$ & $\mathrm{T}(\mathrm{s})$ & \\
\hline M_A & 0.23 & 6 & & & Monochromatic \\
\hline $\mathrm{C}_{-} \mathrm{A} 2$ & 0.23 & 6 & 0.04 & 30 & Combination \\
\hline $\mathrm{C}$ A4 4 & 0.23 & 6 & 0.04 & 15 & Combination \\
\hline $\mathrm{B}$ A 1 & 0.16 & 5.4 & 0.16 & 6.6 & Bi-chromatic \\
\hline B_A2 & 0.16 & 4.6 & 0.16 & 7.1 & Bi-chromatic \\
\hline R_A1 & 0.32 & 6.7 & & & Random GF $=0.96$ \\
\hline R_A2 & 0.32 & 6.7 & & & Random GF $=1.08$ \\
\hline
\end{tabular}

Table 2. Summary of SUSCO targeted wave conditions.

Considerable efforts were made to co-locate the ADVs, OBSs and ADSs, in order to achieve good spatial resolution during the experiments. The co-location of this equipment will make it possible to study the effect of run-up events, swash-swash interactions in the velocity field and the measured suspended sediment events. Most of the ADV locations coincided with the OBSs on the cross-shore locations along the inner surf and swash zones, as can be seen in Table 1 and Figure 1. However, they did not coincide in the long shore direction (perpendicular to the wave flume walls). The ADVs were usually located at $0.6 \mathrm{~m}$ from the right flume wall, while the OBSs were located in the same cross-shore location and vertical elevation with respect to the bed level but close to the opposite wall. The vertical elevations with respect to the sandy bed were checked at the beginning of each test. A detailed flume set-up, instrumentation and complete report of the experiments can be found in Vicinanza et al. 2009 and Baldock et al. 2011.

ADV velocity data were processed and spike noise was eliminated using the method developed by Goring and Nikora (2002). Low quality data, where signal to noise ratio or signal amplitude was below $75 \mathrm{~dB}$ for signal amplitude and $15 \mathrm{~dB}$ for signal to noise ratio, were discarded. The quality of velocity data collected was high and only a low proportion of the total information acquired was dismissed (the average percentage of bad quality data was around $0.02 \%$ and the maximum 
percentage of bad data for all tested conditions was $0.5 \%$ ). Each OBS deployed was calibrated using CIEM sand samples and a replica of the apparatus developed by Downing and Beach (1989).

In order to describe the profile evolution along the different measured profiles, the recovered bathymetric information was processed to obtain the shoreline position, bar and berm main features (location, height and volume). The shoreline position before each hydrodynamic test was obtained from the crossing point of the mean water level in steady conditions with each bathymetric survey. The bar peak refers to the point of maximum bathymetric height in the bar formation, which is also the point with minimum water depth on the bar (see Figure 4-b for an example where P4 has been used to measure the bar and berm parameters). The bar location refers to the distance of the bar peak to the original shoreline position (using the $\mathrm{x}$-coordinate system defined in the second paragraph of this section). The bar height refers to the height of the bar peak relative to the original profile at this same cross-shore location at the beginning of the runs (distance between the red line P4 and the dashed grey line P0). The bar volume is obtained from the integral of the bar area (between P4 and P0). The bar beginning and end, which are used to obtain the bar volume, are considered as the crossing points of the studied bar with the initial profile $\mathrm{P} 0$ (the crossing points are depicted in dashed dark green lines in Figure 4-b). The berm peak is defined as the point of maximum positive difference between the measured and initial profiles within the emerged part of the profiles (P4 and P0 for the case presented). The berm volume is again obtained from the integral of the berm area (the crossing points are again depicted in dashed dark green lines in Figure 4-b).

\section{Results}

\subsection{Erosive conditions}

\section{Profile dynamics}

Figure 4 shows the bottom evolution at three different time steps and for the six different erosive wave conditions. The initial profile (P0) at the beginning of each tested wave condition is shown in dashed grey, the bottom evolution after one run (P1, 24 minutes of waves) is shown in black, the profile (P3, 96 minutes of waves) in blue, and the final acquired profile after 6 runs (P4, 144 minutes of waves) in red. Figure 5 summarizes the information relating to the bar (x-location, height and volume) and shoreline evolution along the 6 runs of each wave condition.

Although all reproduced Erosive wave conditions have the same energy, the bar distance to the shoreline is significantly higher for Bichromatic and Random waves (magenta, green, red and grey 
in Figure 5-a) as compared to the values obtained for Monochromatic and Combination waves (black and blue lines respectively). The monochromatic wave condition is the one that generates a bar closer to the shoreline $(-6.3 \mathrm{~m})$, a shorter bar height and the smaller bar volume (black lines in Figures $5 \mathrm{a} \mathrm{b}$ and c, respectively). Although the combination waves (Figure 4-b, and blue line for Figure 5) show closer results to M_E, the bar distance to the initial shoreline and the bar volume are larger than the monochromatic case due to the $15 \mathrm{~s}$ free long wave perturbation. The Bichromatic and Random conditions present a bar with an average distance to the shoreline of $11 \mathrm{~m}(3.7$ and $3 \mathrm{~m}$ further than M_E and C_E4) with a standard deviation of that mean of $0.47 \mathrm{~m}$. The Bar volumes under Bichromatic and Random conditions are not as homogeneous as their bar location. The bar for B_E1 condition is higher and has a bar volume of $3.2 \mathrm{~m}^{3}$, which is $75 \%$ larger than the mean bar volume for B_E2 and both random conditions (mean volume of $1.83 \mathrm{~m}^{3}$ with a standard deviation of $\left.0.13 \mathrm{~m}^{3}\right)$.

The profile evolution towards an equilibrium state is considered here by looking at the main bar features of the measured profiles. The M_E tested condition shows a fast evolution towards an equilibrium of the main bar characteristics; smooth changes occur after the first profile (P1), while a cross-shore bar displacement of $2 \mathrm{~cm}$ (in the range of the measurement or computational errors) is measured between P3 and P4 with constant values for bar height and volume. The combination waves (Figure 4-b, and the blue line for Figure 5) lead to closer results to M_E in terms of a fast morphological development at the initial tests that nearly reached an equilibrium state after the initial runs (from $\mathrm{P} 3$ to $\mathrm{P} 4$, the bar location and volume change rate is $2 \%$ and $13 \%$ respectively; the change rate of the selected bathymetric features is computed by obtaining the volume difference between the studied value at P3 and P4, and by dividing this difference by the value at P3). In contrast, the Bichromatic conditions (Figure 4-c and d, and red and green lines in Figure 5) produce a bar after the first run. However, this bar does not reach an equilibrium situation and keeps on evolving during the last two measured profiles. The bar cross-shore displacement between P3 and P4 is just 3.6\% and 1\% for B_E1 and B_E2 respectively (the bar displacement percentage are computed by obtaining the increase in the bar crest distance, relative to the shoreline, between P3 and $\mathrm{P} 4$ and dividing this value for the measured distance at P3 profile). The continuous bar displacement towards offshore positions, under B_E1 and B_E2, requires a big increase in sand volumes (Figure 5-c). The bar volume change rate between profiles P3 and P4 is $22 \%$ and $24 \%$ for B_E1 and B_E2 respectively. Random conditions are the ones that result in the slowest bar growth along the initial profiles. The bar is merely an undulation after the initial run (black line in Figures 4-e and $\mathrm{f}$ ). But are also the conditions that result in larger bar cross-shore displacements between P3 and P4 (5\% for both random conditions) and bigger bar volume change rates (15 and 75\% for R_E1 
and R_E2 respectively between P3 and P4). For both cross-shore and bar volumes, changes can be observed from the slope of grey and magenta lines on the top and bottom left panels in Figure 5.
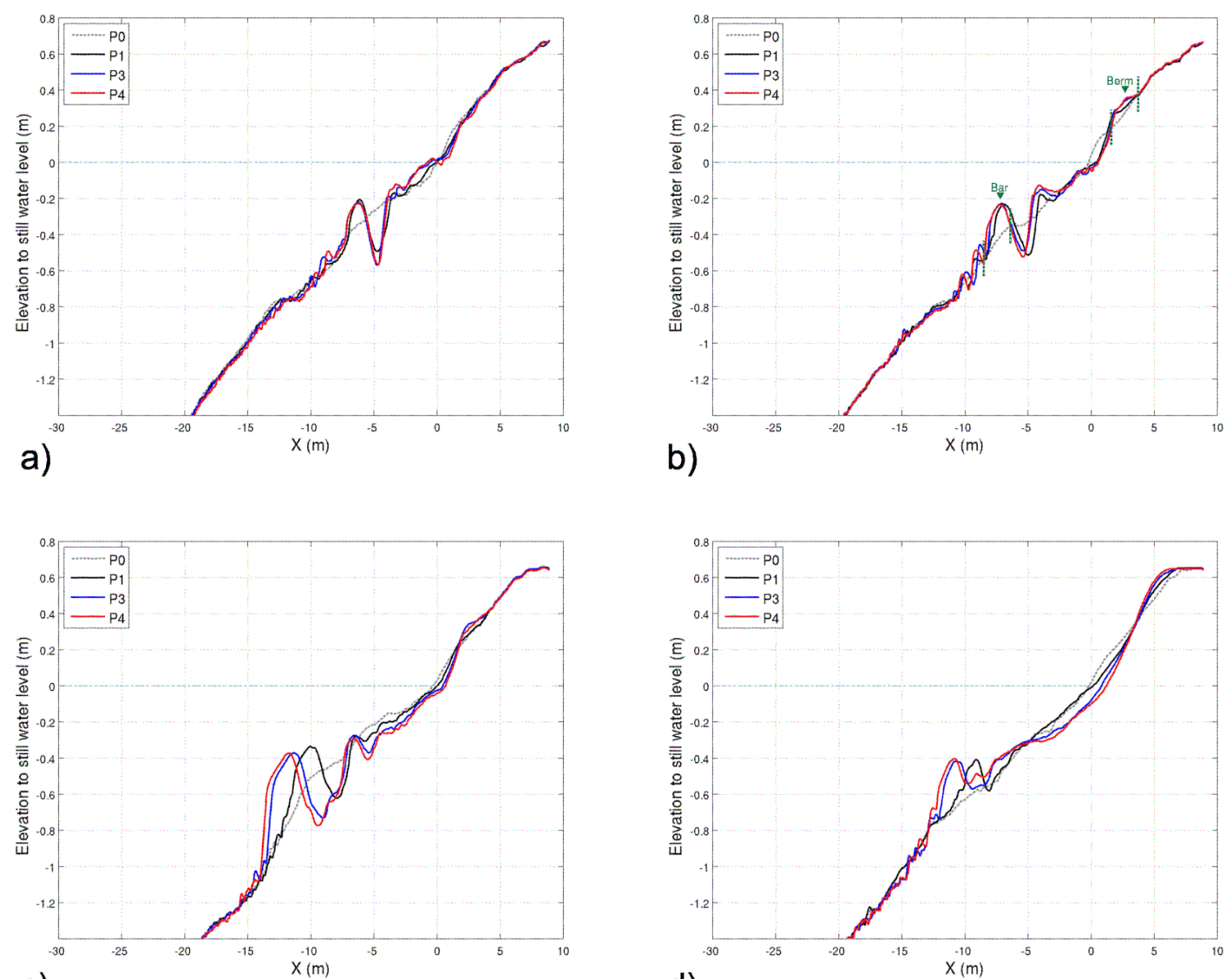

c)

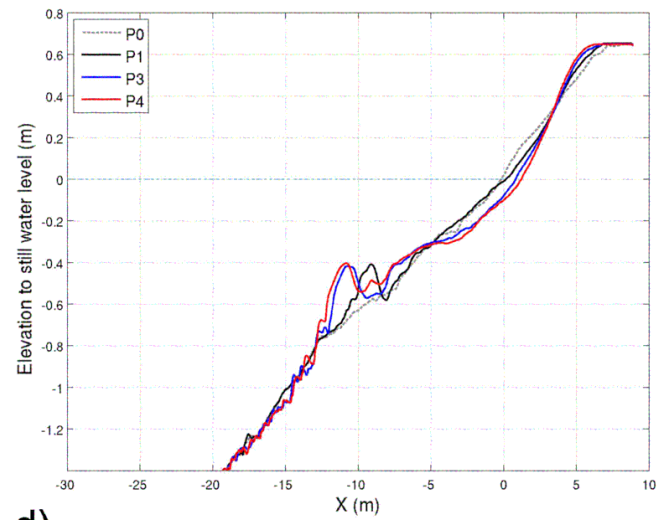

d)

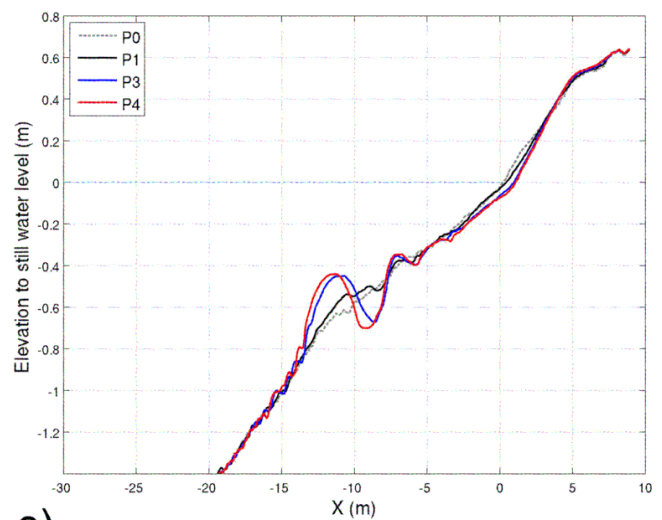

e)

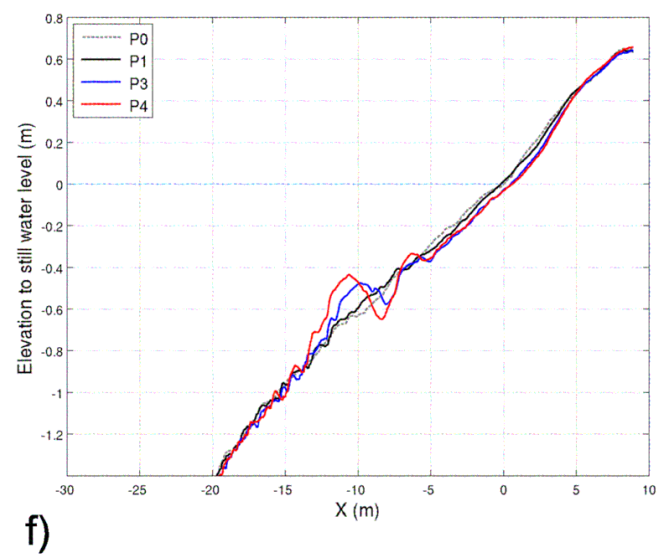

Figure 4. Bottom profile evolution for M_E (a), C_E4 (b), B_E1(c), B_E2(d), R_E1(e) and R_E2(f) wave conditions. The dashed grey line shows the initial 1/15 slope at $\mathrm{P} 0$, the black line shows the bottom profile at P1 (after run 1), the blue line shows the profile at P3 (after run 4), and the red line shows the final measured profile at P4 (after run 6). 

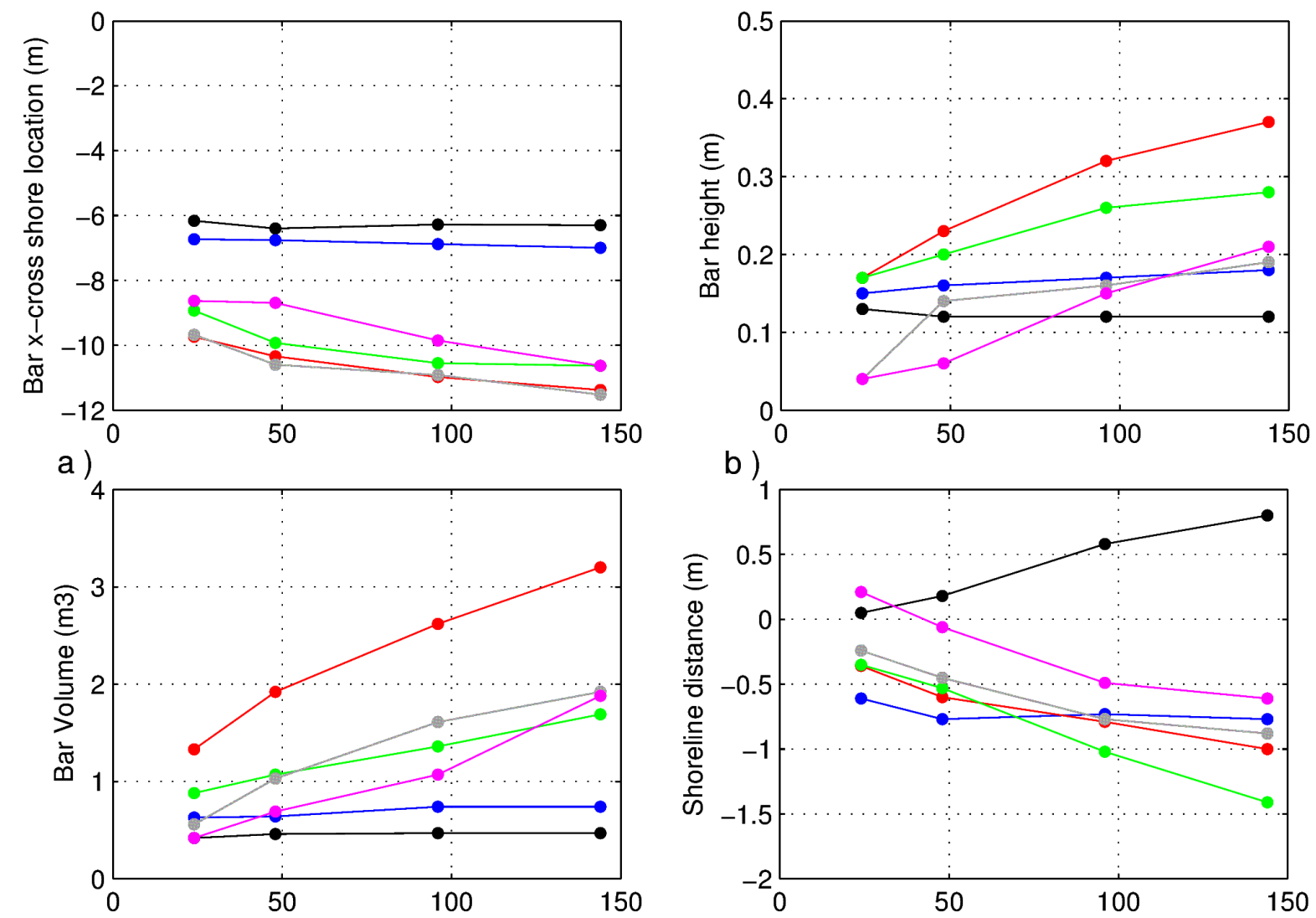

C)
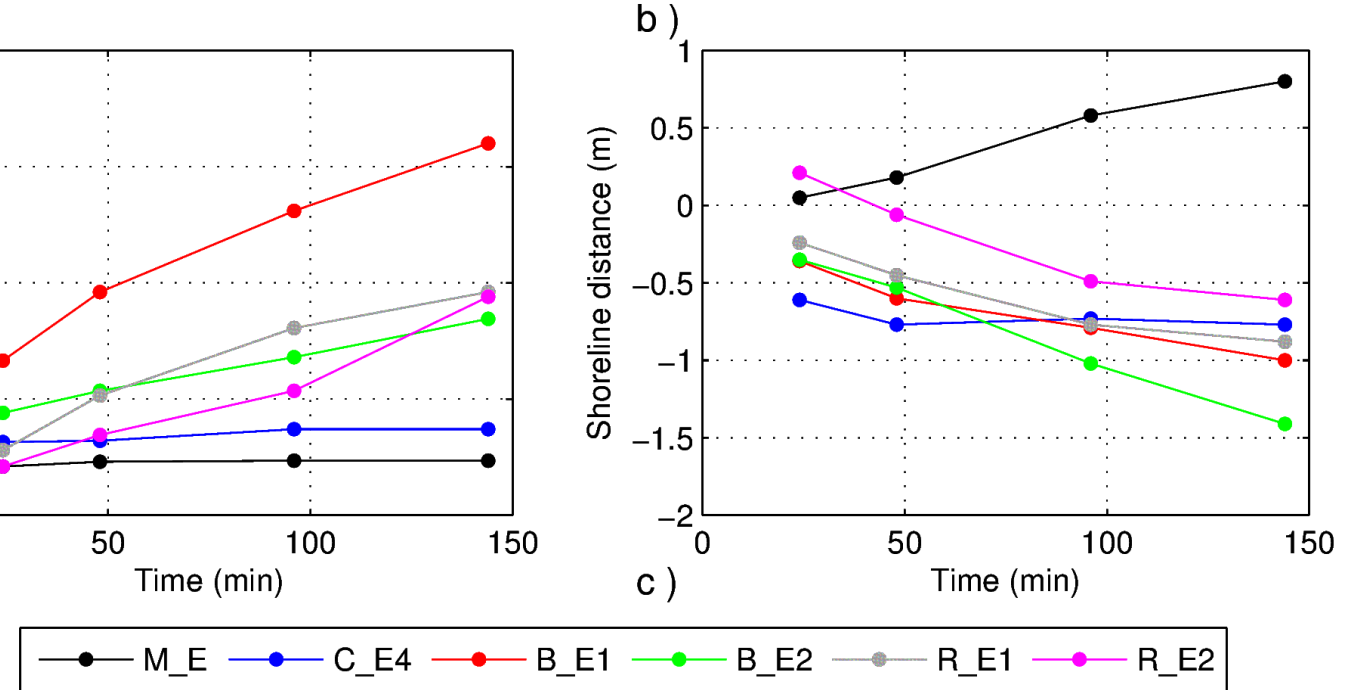

Figure 5. Evolution along the different runs of the main profile features for each Erosive wave condition. The different topographic features have been defined in relation to the initial profile for each test $\mathrm{P} 0$. The $\mathrm{x}$-location refers to the distance of the bar, berm or shoreline towards the shoreline position at the initial profile ( $\mathrm{P} 0)$ in still water conditions.

When considering the sand volumes between the initial (P0) and final (P4) profiles for each wave condition, the maximum measured volume mismatch is $0.68 \mathrm{~m}^{3}$ for $\mathrm{R}$ E 2 wave condition (mean volume difference for all wave cases of $0.41 \mathrm{~m}^{3}$ ). This sand volume difference is in the same order of magnitude as the precision of the mechanical profiler, accounting for $0.4 \%$ of the total computed active sand volume (from the maximum run-up limit to the closure depth of $1.2 \mathrm{~m}$ ). The fact that there is a broad loss of sediment between the initial profile and the last profile is consistent with the sand compaction observed during consecutive wave runs.

\section{Wave height, velocity and SSC spectrum analysis}

Figure 6 shows the computed power spectrum analysis for water surface (top panel), velocity (mid panel) and suspended sediment concentration (lower panel) for the different M_E (a), C_E4 (b), 
B_E1 (c) and B_E2 (d) wave conditions. The spectrum analysis was performed to study the behaviour of the different parameters measured along the flume (wave height, velocity and suspended sediment concentration) for the various tested conditions. The power spectrum was computed from Fourier transform using a modified Welch (averaged) periodogram, dividing each signal into 8 segments with a 50\% overlap; each section was windowed with a Hamming window technique.

The water surface signal (top panel in each sub-figure) was studied using WG, PPT and ADS. The initial resistive wave gauge considered in this spectral analysis is located more than $20 \mathrm{~m}$ after the wave paddle $(\mathrm{x}=-55.4 \mathrm{~m}, \mathrm{WG})$, on the flat concrete section of the flume to characterize the generated signal. The PPT at $\mathrm{x}=-13.8 \mathrm{~m}$ is located along the $1 / 15$ slope or along the initial part of the bar slope depending on the test run. It was selected to represent the wave behaviour during shoaling and before breaking. Finally, the PPT located at $x=-4.3 \mathrm{~m}$ and the ADS at $\mathrm{x}=-1.7 \mathrm{~m}$ were selected to characterize the wave height behaviour at the surf zone. The water depth of the last measurement point located in the surf zone ranges between $0.12 \mathrm{~m}$ at the beginning of each set of wave conditions and $0.07 \mathrm{~m}$ or $0.21 \mathrm{~m}$ for the final test of M_E and B_E2 wave conditions respectively.

The velocity and SSC measurements (mid and lower panel in each sub-figure) were all located within the surf and swash zones. All ADVs were located between the bar and the shoreline in permanent submerged areas in still water conditions. The three ADV locations analyzed here are at $x=-5.7,-2.7$ and $-0.5 \mathrm{~m}$ (solid black pentagrams in Figure 1). Similarly, the OBSs were deployed behind the bar but in this case the studied equipment was located at $\mathrm{x}=-2.7,-0.5$ and $0.5 \mathrm{~m}$ (empty red circles in Figure 1).

The design wave frequency $(0.271 \mathrm{~Hz})$ within the Monochromatic wave tested (M_E) at Figure 6-a controls the water surface elevation, velocity and SSC on the different spectrums at all studied locations. The energy of the water surface and velocity spectrum reduces when moving towards the shoreline, in line with wave breaking energy dissipation. However, the suspended sediment concentration power spectrum increases from $x=-2.7$ to $x=-0.5 \mathrm{~m}$. This is consistent with energetic sediment transport theories (Bagnold 1966), i.e. larger energy dissipation is translated in a larger sediment transport capacity. Moreover, previous studies indicate larger sediment concentration closer to the shoreline (Osborne and Rooker, 1999). 
Combination waves (C_E4) at Figure 6-b, present a water surface spectrum energy content for the long wave significantly lower (1\%) than for the short targeted wave. The long wave targeted peak $(0.065 \mathrm{~Hz})$ is apparent at the velocity spectra with a relative contribution to the total energy due to the small amplitude of the long wave component. Interestingly, the long wave frequency when computing the SSC power spectra at the shoreline ( $x=-0.36 \mathrm{~m}$, grey line) has almost the same energy as the targeted short wave despite its relative small contribution in terms of water surface elevation and flow velocity. Alsina and Cáceres (2011) showed that incident broken waves occurring in the trough of a long wave water level elevation (waves arriving over minimum depth) were very efficient in producing high suspended concentration events.
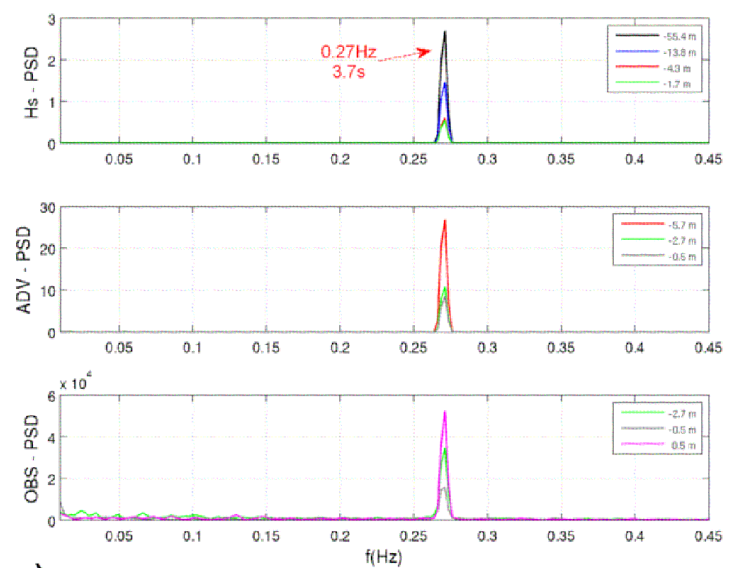

a)
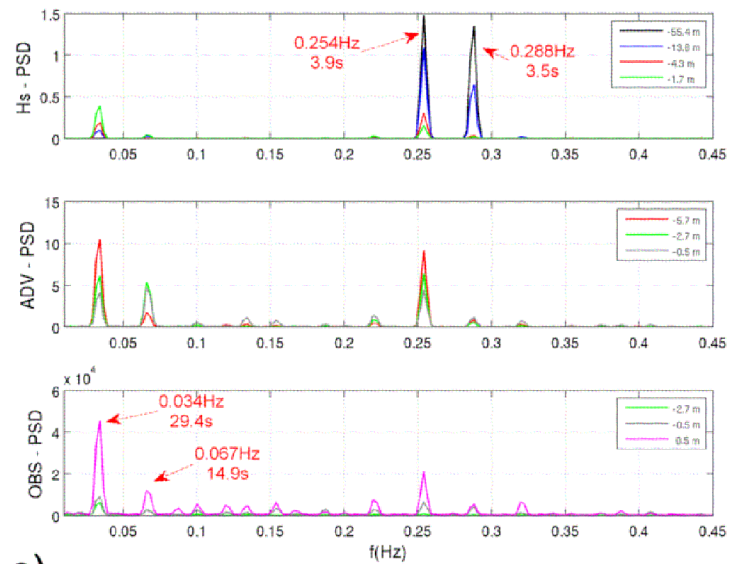

c)
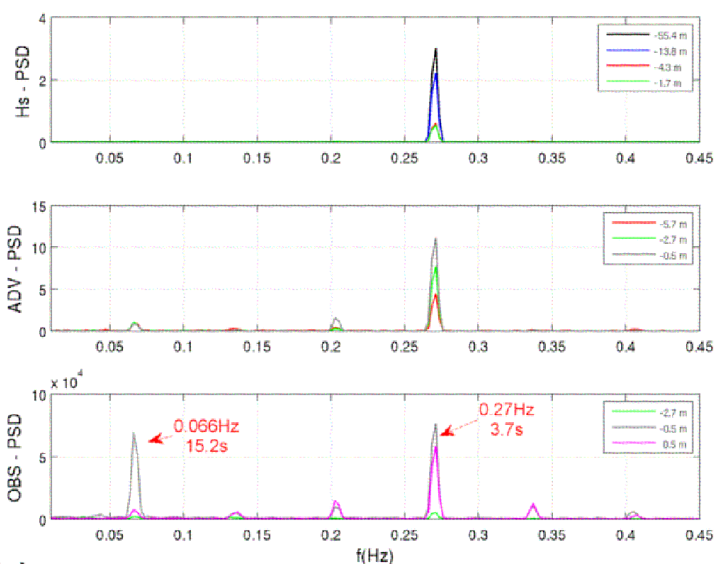

b)
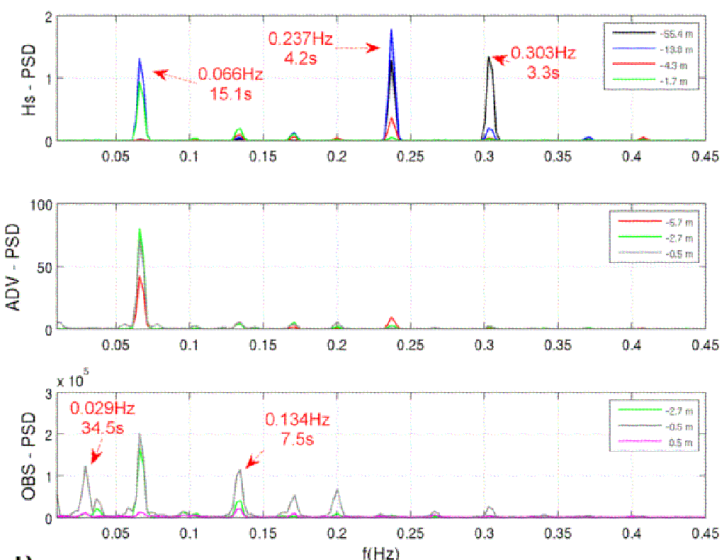

d)

Figure 6. Computed power spectrum for water surface (top panel), velocity (mid panel) and suspended sediment concentration (lower panel) for M_E wave conditions in section a), while section b) is for C_E4, c) for B_E1 and d) for B_E2 wave conditions.

Both Bichromatic conditions, B_E1 and B_E2 on Figures 6-c and d respectively, follow the same pattern where the targeted waves control the water surface elevation previous to breaking (black line). During the breaking process there is an energy transfer towards the wave group frequency of 
the spectral energy on the water surface elevation. Velocity and SSC spectrums, computed from measurements behind the bar and therefore after the main breaking in the surf zone, are mainly controlled by the wave group (29.4 and $15.1 \mathrm{~s}$ for B_E1 and B_E2 respectively).

\section{Time domain analysis}

The time domain analysis focuses mainly on the inner surf and swash zone where most of the ADVs and OBSs have been deployed. The measured velocities for all tests show a mean negative value at the various cross-shore measurement locations. All measurement locations are found between the bar and the shoreline after wave breaking, and the vertical elevation of the ADV with respect to the bed is between 9 and $20 \mathrm{~cm}$. The mean velocities for the 6 tested wave conditions, when considering the 3 different ADV locations, does not show significant differences. The average mean velocity for all locations and tested conditions is $-0.21 \mathrm{~m} / \mathrm{s}$ with a low standard deviation of 0.03 $\mathrm{m} / \mathrm{s}$. The maximum and minimum averaged velocities relate to tests B_E1 $(-0.17 \mathrm{~m} / \mathrm{s})$ and M_E ($0.27 \mathrm{~m} / \mathrm{s}$ ) measured at the ADV located at $\mathrm{x}=-0.5$ and $-2.75 \mathrm{~m}$ from the shoreline, respectively. Behind the bar (shoreward), the wave group period dominates the velocity time series in all Bichromatic conditions. In order to capture this phenomenon, the velocities are phase-averaged at the group period and then the maximum (positive and shoreward directed) and minimum (negative and offshore directed) mean values are computed (Table 3). The most offshore location at Table $3, x$ $=-5.7 \mathrm{~m}$ must be carefully handled due to the proximity of this measurement spot to the bar formation (-6.4 and -7.2 m) for M_E and C_E4 respectively, and therefore to the influence of wave breaking at and behind the bar. The computation of the Turbulent Kinetic Energy from the ADV at $\mathrm{x}$ $=-5.7 \mathrm{~m}$ supports this idea, showing the increase in turbulence at the same time that maximum positive velocity peaks are recorded for M_E and C_E4 conditions. The other two measurement locations, $\mathrm{x}=-2.7$ and $-0.5 \mathrm{~m}$ from the shoreline, show a clearer pattern in which the shoreward and offshore directed maximum velocities increase with the greater control of the wave group. Both bichromatic wave conditions (B_E1 and B_E2) show significantly higher averaged peak velocity values (maximum and minimum) than the data measured for M_E and C_E4 conditions.

The maximum run-up values have been computed based on the different Acoustic Displacement Sensors deployed in the swash zone (Table 4). The values (thickness and location) of the two ADSs at each run-up event are used to create a linear projection of the run-up, considering the beachface slope. The computation is performed at different ADS locations, in order to ensure consistency of the computed measurement, and a final average value is obtained from the 10 larger run-up events of each time series. 


\begin{tabular}{|c|c|c|c|c|c|c|}
\hline \multirow{2}{*}{ Test } & \multicolumn{2}{|c|}{$\mathrm{U}(\mathrm{x}=-5.7 \mathrm{~m})$} & \multicolumn{2}{c|}{$\mathrm{U}(\mathrm{x}=-2.7 \mathrm{~m})$} & \multicolumn{2}{c|}{$\mathrm{U}(\mathrm{x}=-0.5 \mathrm{~m})$} \\
\cline { 2 - 7 } & shoreward & offshore & shoreward & offshore & shoreward & offshore \\
\hline M_E & $0.56(0.19)$ & $-0.74(0.09)$ & $0.24(0.04)$ & $-0.70(0.05)$ & $0.13(0.08)$ & $-0.73(0.08)$ \\
\hline C_E4 & $0.54(0.10)$ & $-0.82(0.12)$ & $0.34(0.03)$ & $-0.69(0.03)$ & $0.26(0.08)$ & $-0.79(0.07)$ \\
\hline B_E1 & $0.81(0.10)$ & $-0.80(0.08)$ & $0.84(0.02)$ & $-0.77(0.03)$ & $1.00(0.14)$ & $-0.96(0.17)$ \\
\hline B_E2 & $1.07(0.07)$ & $-1.27(0.07)$ & $1.35(0.19)$ & $-1.23(0.10)$ & $1.62(0.14)$ & $-1.62(0.21)$ \\
\hline
\end{tabular}

Table 3. Maximum and Minimum (positive shoreward and negative offshore directed) mean phase-average velocity values. The standard deviation of the values for the different runs are shown in grey and brackets. All values are in $\mathrm{m} / \mathrm{s}$.

\begin{tabular}{|c|c|c|c|c|}
\hline Test & M_E & C_E4 & B_E1 & B_E2 \\
\hline Run-up (m) & 3.1 & 3.1 & 4.4 & 5.7 \\
\hline
\end{tabular}

Table 4. Maximum run-up events extrapolated from the run-up height measurements at the different ADS sensors.

\subsection{Accretive conditions}

The laboratory protocol for Accretive conditions was slightly different than the one already shown for Erosive conditions (Figure 3). There are two differences: i) the reshaping to a 1/15 slope after each Accretive wave condition was performed until $\mathrm{x}=-5 \mathrm{~m}$, which was identified as the limit of the most active sediment transport under the selected Accretive conditions; ii) two Erosive runs (R_E1) were performed after the handmade reshaping so that all Accretive conditions start from the same erosive situation at the surf and swash zone. In this way the scheme for Accretive conditions is set to be: handmade 1/15 slope, plus 2 Erosive random runs, plus 6 Accretive runs following the scheme shown in Figure 3.

It is worth noting that the Energy content of M_A condition was half the Energy accounted for in all the other Accretive conditions, as previously explained in section 2. In any case the information has been included here as its comparison and outputs are consistent and worth remembering from the authors' viewpoint.

\section{Profile dynamics}

Figure 7 shows the bottom evolution for the Accretive tested wave conditions. All conditions, with the exception of case (R_A1), show a shoreward sediment transport. The first three cases a, b and c in Figure 7 (for Monochromatic M_A, and both Combinations C_A2 and C_A4 conditions) show a clear berm formation while there is some erosion in the surf zone, thus increasing the beach face slope. The M_A case shows a maximum berm height of $0.12 \mathrm{~m}$ at $\mathrm{x}=0.66 \mathrm{~m}$, containing a sand 
volume of $0.63 \mathrm{~m}^{3}$, while the two Combination cases show bigger berms with heights of 0.17 and $0.19 \mathrm{~m}$ located at 1.04 and $1.06 \mathrm{~m}$ from the shoreline for C_A2 and C_A4 respectively. The bigger berm sand volume corresponds to C_A4 with $1.16 \mathrm{~m}^{3}$ while C_A2 has a berm volume of $0.93 \mathrm{~m}^{3}$. The remaining tests have a negligible berm but both Bichromatic cases promote the formation of a secondary bar where the waves are breaking. From the net sediment transport under Accretive conditions (Monochromatic, Combination and Bichromatic), there is a clear sediment transport towards the shoreline, while the sediment transport is negligible under random Accretive wave conditions. Most of the Accretive tested conditions do not seem to have reached an equilibrium situation (as can be observed when comparing P3 and P4 on Figure 7 and from the data relating to the bar, trough and berm main features), with the exception of the B_A1 case. Under this Bichromatic condition the profile has developed a significant secondary bar, where waves are breaking, and the transported sand volumes between P3 and P4 is nearly negligible in the surf and swash zone. The difference measured between both profiles has a mean value of $0.003 \mathrm{~m}$ with a standard deviation of $0.014 \mathrm{~m}$ when considering the active profile between the trough of the primary bar $(\mathrm{x}=-8.5 \mathrm{~m})$ until the maximum run-up measurement $(\mathrm{x}=2.6 \mathrm{~m}$, reported in Table 6). The Random Accretive wave case (R_A1) shown on Figure 7-f is, without reaching the equilibrium state, already a "stable" situation along all gathered profiles under the tested waves. The maximum change that occurs between all measured profiles takes place around the shoreline where the maximum erosion measured is $-0.05 \mathrm{~m}$. The maximum standard deviation between the different R_A1 profiles is $0.02 \mathrm{~m}$ (at $\mathrm{x}=-1 \mathrm{~m})$. The profile evolution of case R_A2 shows a similar pattern to R_A1 with negligible sediment transport along the 6 time series.

\section{Wave height, velocity and SSC spectrum analysis}

The analysis shown here was based on the same data processing as that described above for Erosive wave conditions. The equipment position is still measured by reference to the shoreline in still water conditions at the beginning of each Accretive wave test. The 2 initial Erosive time series prior to the Accretive conditions erode the shoreline from the $1 / 15$ slope around $0.5 \mathrm{~m}$. Given that the measurement equipment was not moved along the different tested conditions, there is a difference of $0.5 \mathrm{~m}$ between the locations of Table 1, the equipment position during the Erosive experiments, and the equipment location at the beginning of each Accretive condition. 


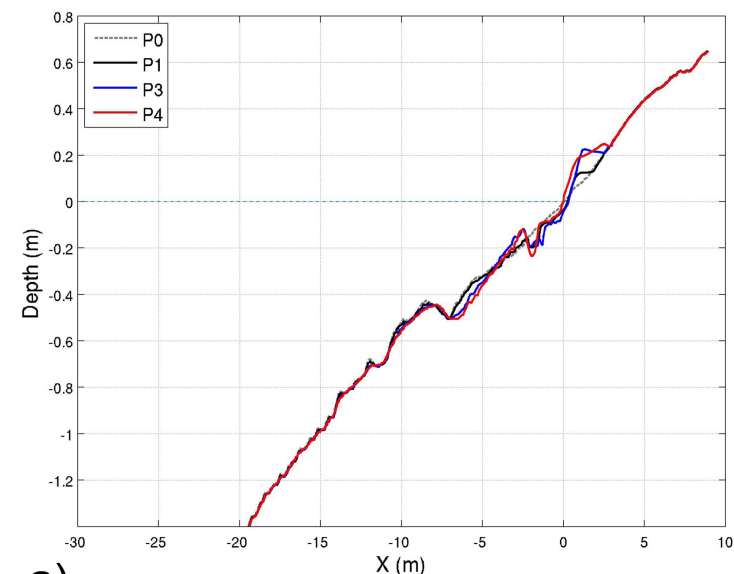

a)

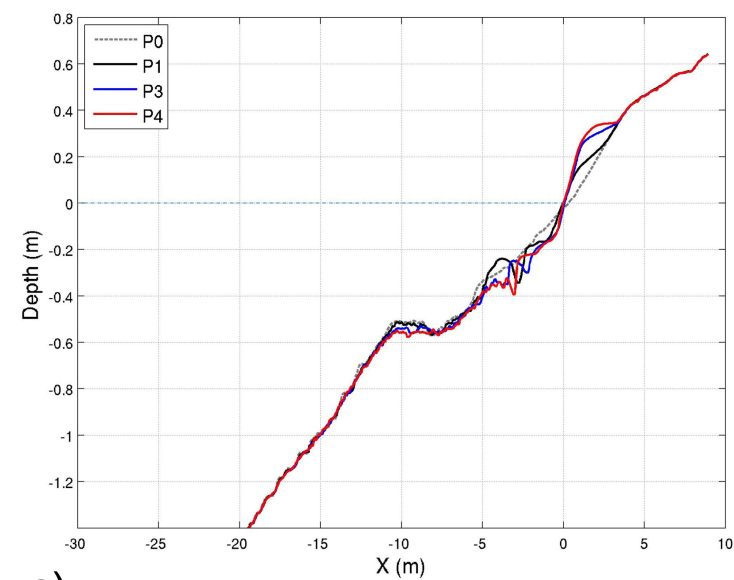

c)

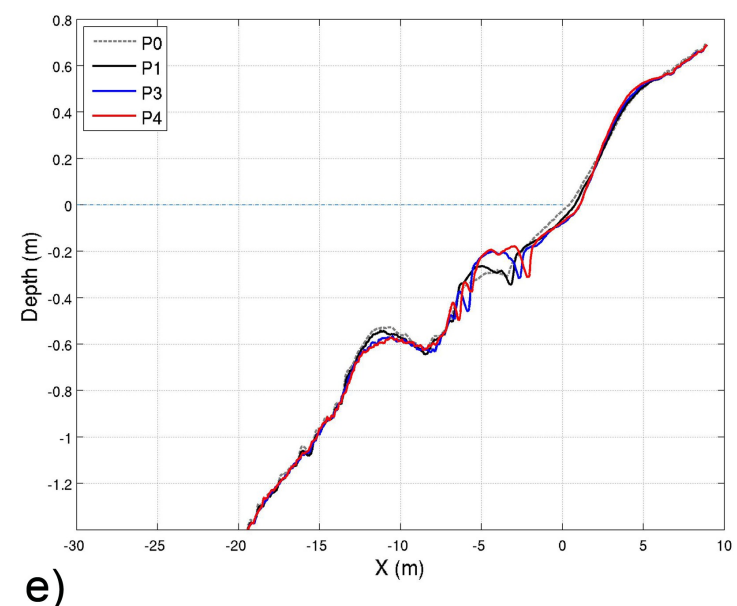

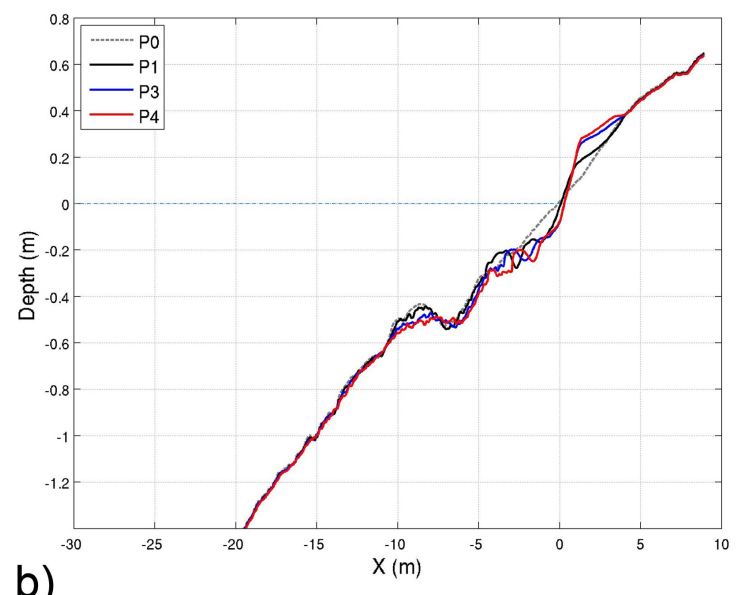

b)

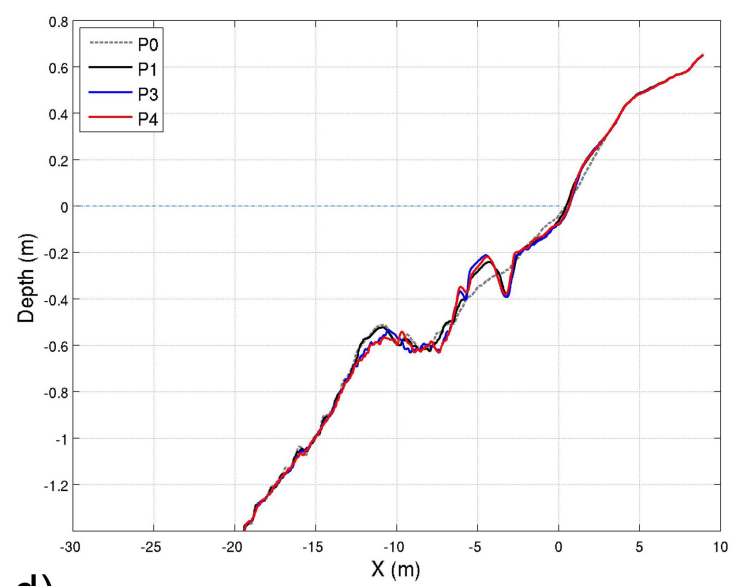

d)

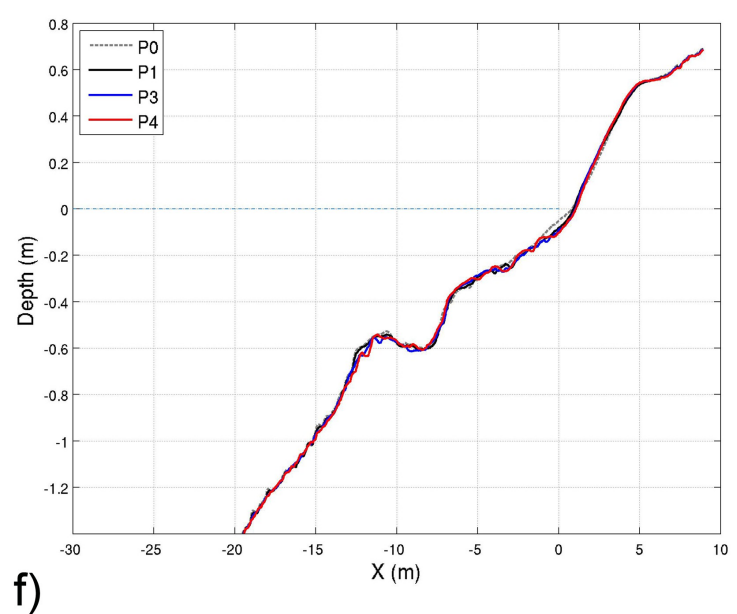

Figure 7. Bottom profile evolution for M_A (a), C_A2 (b), C_A4(c), B_A1(d), B_A2(e) and R_A1(f) wave conditions. The dashed grey line shows the initial 1/15 slope P0, the black line shows the bottom profile at P1 (after run 1), the blue line shows the profile at P3 (after run 4), and the red line shows the final measured profile P4 (after run 6).

Figure 8 shows the computed power spectrum for water surface elevation (top panel), velocity (mid panel) and suspended sediment concentration (lower panel) for the Accretive wave conditions 
described in Table 2. Figure 8-a shows the control of water surface elevation, velocity and suspended sediment concentration patterns due to the short targeted Monochromatic wave conditions (M_A). Two different Combination waves are studied in Figure 8-b and 8-c. The difference between both wave conditions is the period of the long free wave (30 s for C_A4 and 15 s for C_A2). Both Combination wave tests show the short targeted waves (peak at $0.176 \mathrm{~Hz}$ ) as the main peak in the spectra for all hydrodynamic measured parameters, while the free long wave has a minor energy content at both conditions (peaks at 0.034 and $0.066 \mathrm{~Hz}$ for C_A2 and C_A4 respectively). The suspended sediment concentration spectrum plot for the Combination cases show major peaks at the incident frequency but also minor peaks at the long wave frequency. This long wave peaks are of less energy compared with the erosive case and suggest a smaller influence of the long wave water surface elevation perhaps due to smaller wave heights to depth ration at these locations compared to the erosive cases.

The Bichromatic conditions show a different scenario (Figure 8-d and 8-e). The targeted short waves are the main energy peaks at the water surface elevation spectrum before breaking (black and blue lines, at $\mathrm{x}=-55.9$ and $-14.3 \mathrm{~m}$ respectively). After breaking the primary waves significantly reduce their energy at the bar (generated around $x=-4.5 \mathrm{~m}$ ). The wave group frequency becomes the main peak after breaking and plays a major role in the velocity and SSC events measured at shoreward locations. Under B_A2 conditions two interesting low frequency peaks appear at the SSC power spectrum (grey and magenta lines, located at $\mathrm{x}=-1$ and $0 \mathrm{~m}$ respectively). One is found between 0.066 and $0.075 \mathrm{~Hz}(13.3$ and $15 \mathrm{~s})$, while the second peak is found at $0.008 \mathrm{~Hz}(120 \mathrm{~s})$. Both peaks will be further studied in the Discussion section.

\section{$\underline{\text { Time domain analysis }}$}

As occurred in the Erosive tests, the mean velocity values of the Accretive conditions are negative, in line with the undertow current (all ADVs perform measurements close to the bottom between 14 and $4 \mathrm{~cm}$ ). While the mean velocity values for the Erosive conditions ranged between -0.27 and $-0.17 \mathrm{~m} / \mathrm{s}$, the Accretive conditions resulted in significantly lower velocity values. The average Accretive mean velocity is $-0.09 \mathrm{~m} / \mathrm{s}$, the maximum for B_A1 wave conditions being $-0.16 \mathrm{~m} / \mathrm{s}$ and the minimum for C_A2 wave conditions being $-0.04 \mathrm{~m} / \mathrm{s}$ (measured at $\mathrm{x}=-3.3$ and $-6.2 \mathrm{~m}$ from the shoreline). The offshore location of $-6.2 \mathrm{~m}$ is now before breaking, and therefore it should not be considered within the mean. If the data gathered at $\mathrm{x}=-6.2 \mathrm{~m}$ are excluded, the mean velocity increases up to $-0.11 \mathrm{~m} / \mathrm{s}$. Monochromatic Accretive data have been excluded from the previous mean calculus due to the lower energy content of this case. 

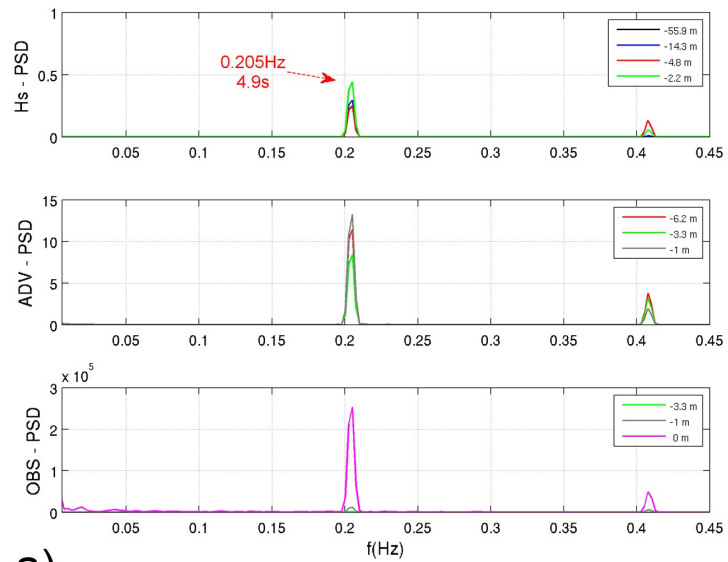

a)
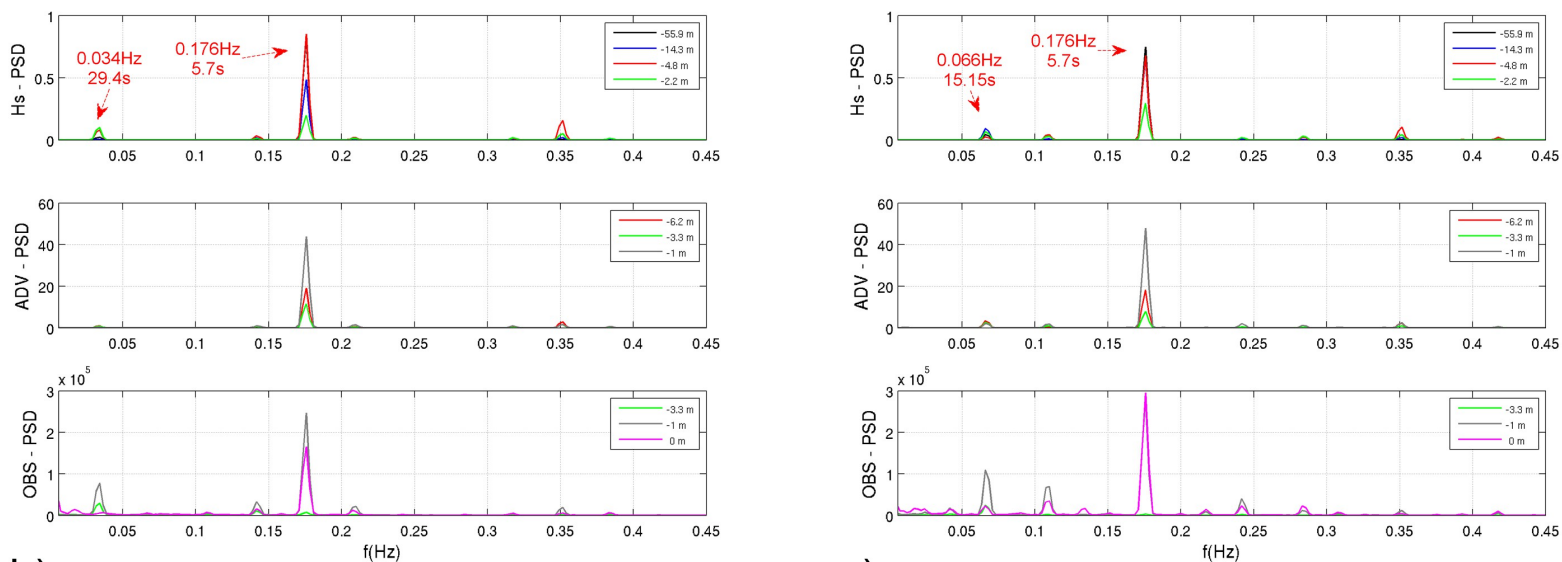

b)

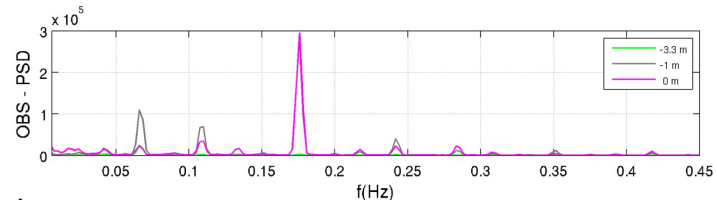

c)
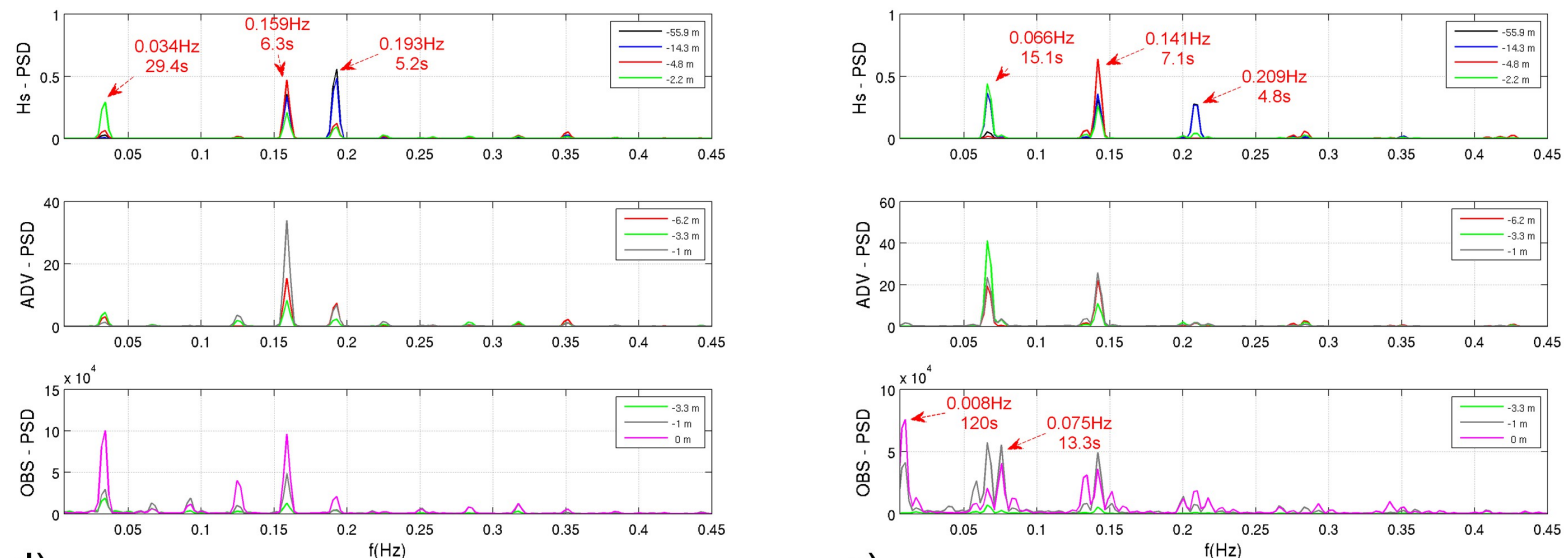

d)

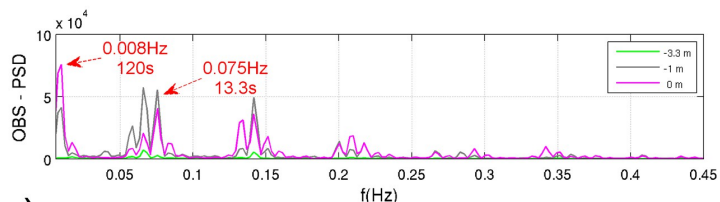

e)

Figure 8. Spectral analyses for M_A (top panel), C_A2 and C_A4 (mid panel left and right respectively), B_A1 and B_A2 (lower panel left and right respectively).

As occurred in the Erosive case, more relevant information can be obtained by computing the maximum and minimum mean values of the phase-average velocities (Table 5). 


\begin{tabular}{|c|c|c|c|c|c|c|}
\hline \multirow{2}{*}{ Test } & \multicolumn{2}{|c|}{$\mathrm{U}$ at $\mathrm{x}=-6.2 \mathrm{~m}$} & \multicolumn{2}{c|}{$\mathrm{U}$ at $\mathrm{x}=-3.3 \mathrm{~m}$} & \multicolumn{2}{c|}{$\mathrm{U}$ at $\mathrm{x}=-1 \mathrm{~m}$} \\
\cline { 2 - 7 } & shoreward & offshore & shoreward & offshore & shoreward & offshore \\
\hline M_A & $0.59(0.03)$ & $-0.47(0.03)$ & $0.68(0.10)$ & $-0.78(0.15)$ & $0.74(0.15)$ & $-0.63(0.09)$ \\
\hline C_A2 & $0.75(0.04)$ & $-0.45(0.05)$ & $0.90(0.15)$ & $-0.90(0.16)$ & $1.21(0.09)$ & $-0.88(0.19)$ \\
\hline C_A4 & $0.77(0.07)$ & $-0.47(0.06)$ & $0.78(0.19)$ & $-0.87(0.19)$ & $1.18(0.09)$ & $-0.89(0.19)$ \\
\hline B_A1 & $1.36(0.27)$ & $-1.05(0.16)$ & $0.65(0.17)$ & $-1.29(0.09)$ & $0.81(0.15)$ & $-0.82(0.04)$ \\
\hline B_A2 & $1.26(0.04)$ & $-1.18(0.05)$ & $1.08(0.08)$ & $-1.15(0.22)$ & $1.01(0.06)$ & $-0.95(0.23)$ \\
\hline
\end{tabular}

Table 5. Maximum and Minimum (positive shoreward and negative offshore directed) mean phase-average velocity values. The standard deviation of the values for the different runs are shown in grey and brackets. All values are in $\mathrm{m} / \mathrm{s}$.

Table 6 shows the maximum run-up computed values within the swash zone. The methodology used to compute the run-up is the same as that previously described for the Erosive conditions.

\begin{tabular}{|c|c|c|c|c|c|}
\hline Test & M_A & C_A2 & C_A4 & B_A1 & B_A2 \\
\hline Run-up (m) & 1.7 & 3.1 & 2.9 & 2.6 & 4.4 \\
\hline
\end{tabular}

Table 6. Maximum run-up events extrapolated from the run-up height measurements at the different ADS positions during the entire time series.

\section{Discussion and data analysis}

The sediment transport profiles are clearly affected by the long wave perturbation and the wave group structure generated within the different tested wave conditions. These differences can be seen not only under Erosive conditions, in the main features at the bar (height and x position) and the trough (height and distance), but also with the presence and location of the berm. The data suggest that the presence of long waves significantly increases the wave breaking area, thereby widening the region of sediment transport.

Part of the data analysis presented here is based on the study of ensemble averaged plots. Each ensemble average is done by selecting the 20 highest SSC episodes within each OBS and run. Within each of this episodes the time of the SSC peak is used as time reference to produce the ensemble. Following this procedure, instead of the classic phase-average analysis of a hydrodynamics property (usually water surface elevation or velocity) favors the identifications of similar events able to produce significant SSC peaks. Despite the procedure is close to the phaseaverage standard data analysis, the time reference used within the ensemble-average is not the phase of the studied property, and therefore the phase can be slightly different within the different ensemble averaged events. 


\subsection{Erosive conditions}

All morphological features (bar and trough x-location, height, volume, etc.) measured under both Bichromatic conditions are closer to the Benchmark conditions (R_E1 measurements) than when Monochromatic or Combination waves are tested. As reported by Baldock et al. 2011, Bichromatic and Random waves present a bigger offshore transport during erosive conditions (greater erosion in the surf zone and higher bar further offshore) than for Monochromatic and Combination cases.

Due to the high repetitive evolution of water surface elevation, velocity and suspended sediment concentration measurements under the tested conditions, the study of the long wave influence has been carried out by means of ensemble average data within each test time series. Figure 9 shows the ensemble averages of the most interesting events; the solid line shows the mean of the ensemble, while the shaded area shows the standard deviation computed during the ensemble process. Despite the fact that some smoothness is introduced when computing the mean of the ensemble average, the authors think that mean values improve the analytical understanding of the physical processes, while the standard deviation information (lightly shaded area) reports the degree of variation around the ensemble average time series. All figures show the water surface elevation (top panel), velocity (second panel), SSC measurements (third panel) over a time span of 40 or 90 seconds depending on the period of the wave group. The fourth panel (lower panel on each figure) shows the computation of suspended sediment fluxes when considering the ensemble mean velocity and the ensemble mean SSC for co-located ADV and OBS equipment. 

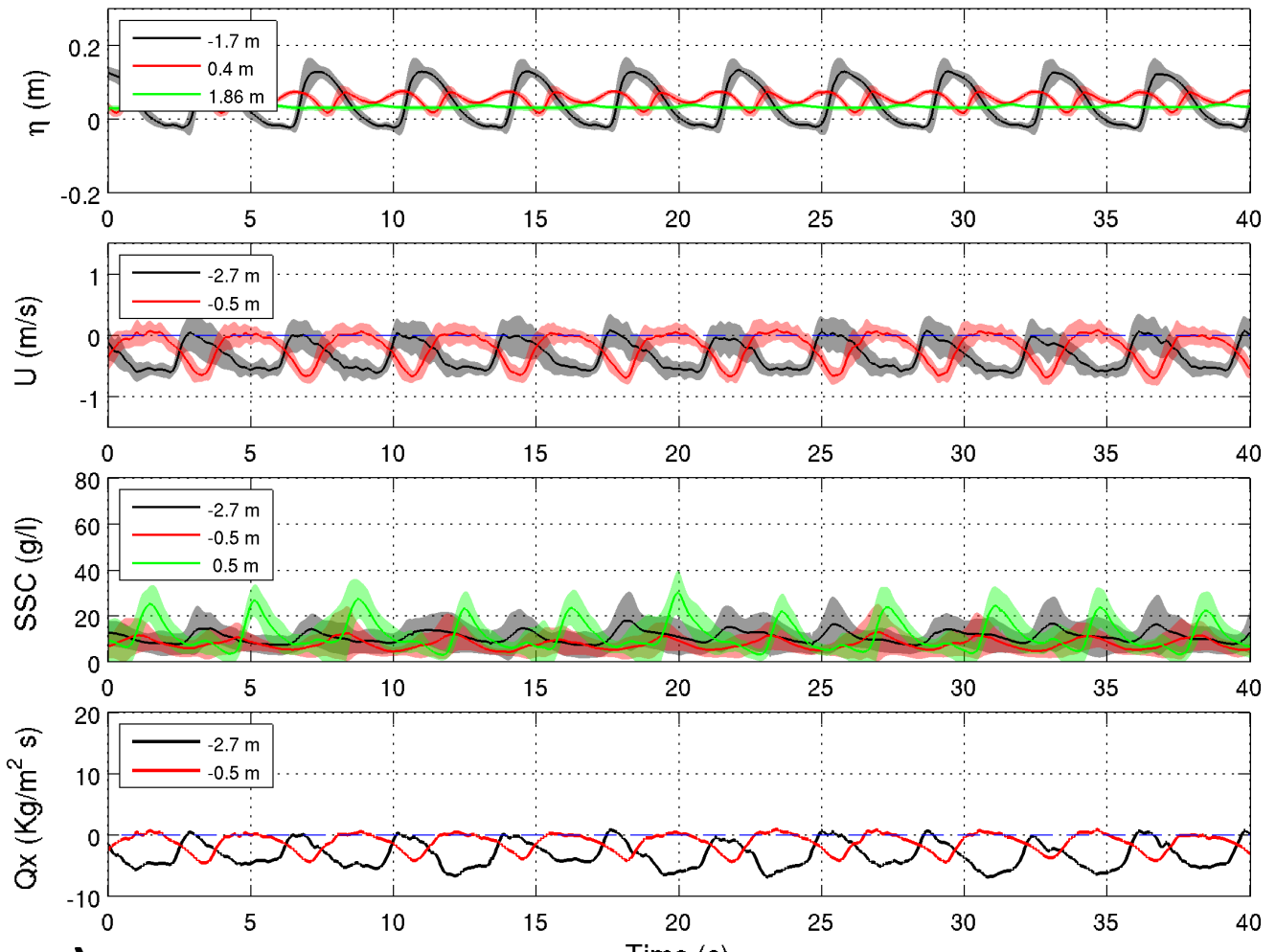

a)
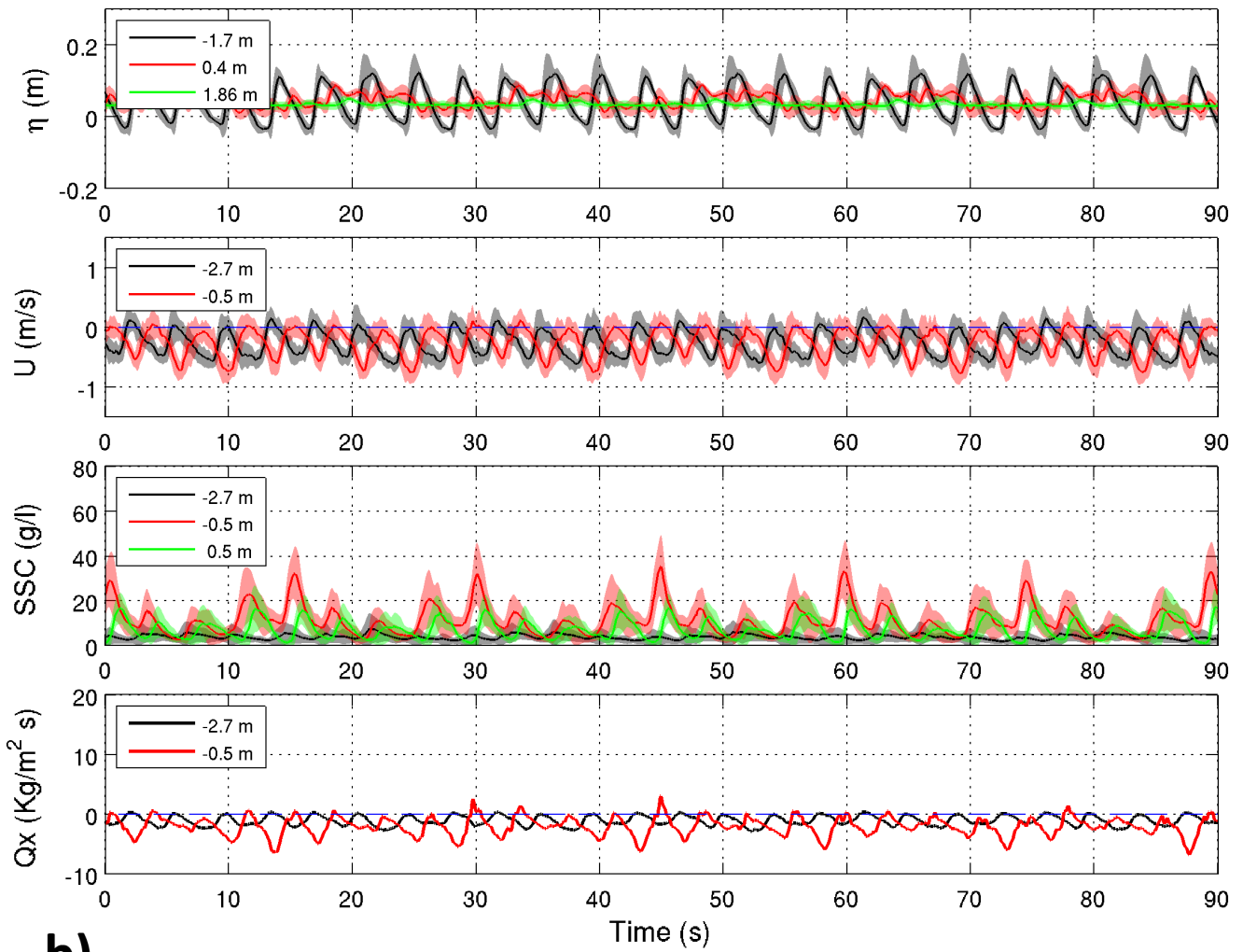

b)

Figure 9. Ensemble average for a) M_E and b) C_E4 wave conditions. Solid line for the mean of the ensemble during the time series, while the lightly shaded area shows the standard deviation of the mean. 
Figure 9-a shows the ensemble average of the highest SSC events measured at M_E wave condition. Every arriving wave (top panel) produces a SSC peak (third panel). The suspended sediment concentration events are linked to the broken waves, the waves break near the bar location $(\mathrm{x}=-6.4 \mathrm{~m})$ arriving as turbulent bores close to the shoreline. The second panel shows the measured velocities (black and red lines) which indicate the mean frequency velocity oscillation shifted by the negative mean flux (mean averaged value of $-0.24 \mathrm{~m} / \mathrm{s}$ ). The suspended sediment fluxes, which are in the fourth panel, show a clear offshore drift due to the mean return flow. This pattern reflects the traditional view that incident waves promote sediment motion from the bed and mean currents (undertow) transport the sediment previously suspended by the waves. The maximum run-up is found at $\mathrm{x}=3.1 \mathrm{~m}$ from the shoreline. The data analysis shows how the interaction between the rundown and the next arriving bore during the first and second runs are the main source of the relevant SSC events found at shoreline locations. The surf zone experiences a sediment deposition process along the different runs and there is a constant local water depth decrease (Figure 4-a). The sediment is deposited, while the shoreline keeps on "eroding" until the end of the Erosive conditions. The local depth of the measurement point at $\mathrm{x}=-2.7 \mathrm{~m}$ decreases from $0.18 \mathrm{~m}$ (Run 1) to the final $0.13 \mathrm{~m}$ (Run 6). The sediment deposition and bathymetric change is maximum in the submerged area close to the shoreline, producing a sediment embankment ( $2 \mathrm{~cm}$ over the MWL). This embankment induces a "fake" shoreline advance of $0.8 \mathrm{~m}$ with respect to the initial shoreline condition. Shoreward of this embankment, the profile is again under the MWL in still water conditions, and the second shoreline point is located at $1.2 \mathrm{~m}$ from the first one that produces a final shoreline erosion of $0.4 \mathrm{~m}$ if the second shoreline point is considered (red line on Figure 4-a).

Figure 9-b shows the mean ensemble average under C_E4 wave conditions. This wave condition shows the superposition of a small amplitude long wave over the monochromatic short waves. The power spectral density analysis (Figure 6-b) shows the predominant role of short targeted waves on water surface elevation and velocity measurements along the flume. The SSC measurements close to the shoreline $(\mathrm{x}=-0.5 \mathrm{~m})$ show a similar amount of energy for the events induced by long (15.2 s) and short (3.7 s) targeted waves, while most of the highest events occur at shoreline positions (x $=-0.5$ and $0.5 \mathrm{~m})$. Figure 9-b shows a clear link between the SSC main peaks $(\mathrm{t}=15,30,45,60$ and $75 \mathrm{~s}$ for OBSs located at $\mathrm{x}=-0.5 \mathrm{~m}$, red line in the third panel) and the wave bores arriving in the trough of the long wave (the long wave pattern can be followed by the wave height measurements at shoreline positions represented by the red line at $\mathrm{x}=0.4 \mathrm{~m}$ in the first panel). The maximum suspended sediment concentration events are measured when short waves arrive in the trough of the long waves. It is also during the initial waves within the wave group when the bigger run-up are measured (around $3.1 \mathrm{~m})$, forcing small shoreward transports $(\mathrm{t}=30$ and $45 \mathrm{~s}$, red line in the lower 
panel of Figure 9-b). The computed transport rates are largely affected by the main return flow (negative velocity). Offshore sediment transport rates occur by the coincidence of negative velocities, predominant along the entire time series at the ADV locations, and suspended sediment events modulated by the long wave. 

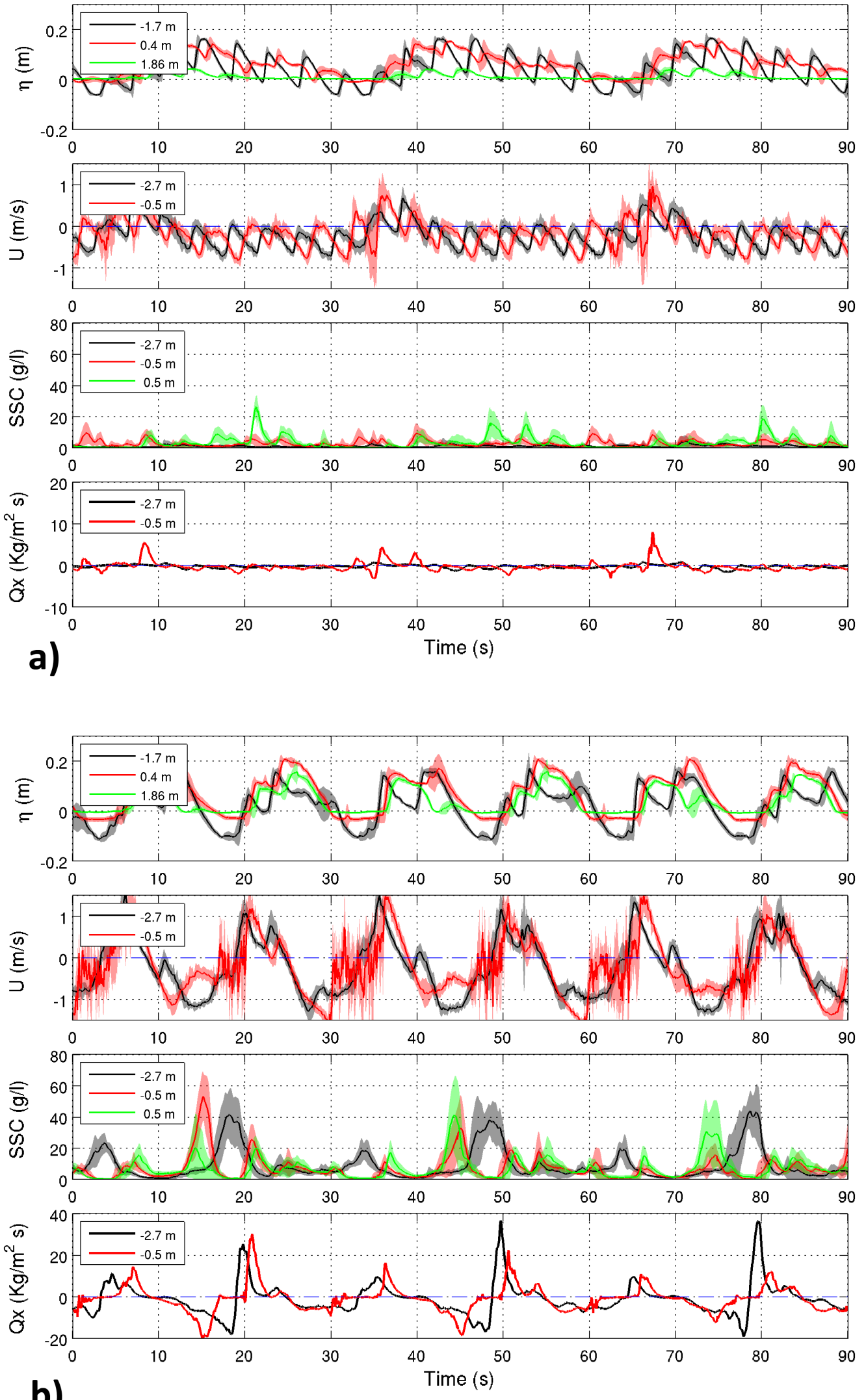

b)

Figure 10. Ensemble average for a) B_E1 and b) B_E2 wave conditions. Solid line for the mean of the ensemble during the time series, while the lightly shaded area shows the standard deviation of the mean. 
The power spectrum analysis for B_E1 tests (Figure 6-c) shows that water surface elevations are controlled by both targeted waves before breaking. On the other hand, the water surface elevation, velocities and suspended sediment concentration events in the surf and swash zone are controlled by the wave group and the short targeted wave with higher period. Figure 10-a shows the ensemble average data for the main SSC events at B_E1 wave condition. The velocity pattern at both measurement locations presents a maximum positive (shoreward) velocity when the new wave arrives after the trough of the long wave $(\mathrm{t}=38$ and $67 \mathrm{~s})$. The remaining time between the positive velocity peaks, the measured velocities have a clear mean negative value that oscillates between 0 and $-0.8 \mathrm{~m} / \mathrm{s}$. The Suspended Sediment Concentration events on Figure 10-a (third panel), tend to happen between the crest and trough of the long wave. For the OBS at $\mathrm{x}=0.5 \mathrm{~m}$ (green line), where the main SSC events are measured, the cases occur at a time equal to 21, 48-52 and $80 \mathrm{~s}$. This SSC event corresponds to wave-backwash interactions (Cáceres and Alsina, 2012). These interactions occur when a wave advances across the front of an existing backwash lens as it recedes down the beach face. The wave-backwash interactions can be strong or weak, depending on the dominant energy of the backwash or incoming wave. Strong wave-backwash interactions are the ones with a predominant backwash and therefore the resulting flux is offshore directed, while the weak wavebackwash interactions are the ones in which the receding backwash has a limited amount of energy and the incoming uprush overrun results in an onshore flow. In the measurements shown, no ADV was deployed at the location of $\mathrm{x}=0.5 \mathrm{~m}$, but the analysis of the ADS deployed in the study area ( $\mathrm{x}$ $=0.4$ and $1.86 \mathrm{~m}$, red and green plots in the first panel of Figure 10-a) allows the recognition of both kinds of interactions under B_E1 test conditions. Strong wave-backwash interactions are the ones that produce the highest SSC events.

The lower panel of Figure 10-a shows a nearly constant small negative sediment flux broken with a positive event, shoreward sediment transport, every 30 seconds (at $t=8,36 / 40$ and $67 \mathrm{~s}$ ). These events occur when a short wave arrives in the trough of the wave group, and are responsible of the maximum run-up measured under this wave condition (green line for the ADS located at $\mathrm{x}=1.86 \mathrm{~m}$ on the top panel of this figure), up to the $4.4 \mathrm{~m}$ run-up excursion reported at Table 4.

Figure 10-b shows the results for B_E2 wave conditions. The main difference between both bichromatic wave conditions is the wider gap between the primary and secondary frequencies. The bigger targeted frequency gap induces the reduction of the wave group period down to $15 \mathrm{~s}$, and reduces the number of short waves within each wave group. When comparing both bichromatic conditions (Tables 2 and 3 and Figure 10-a and 10-b), B_E2 shows significantly bigger short waves arriving at the shoreline, higher velocities (shoreward and offshore directed), and bigger suspended 
sediment concentration events (linked to waves breaking at the shoreline and due to strong wavebackwash interactions). B_E2 data show higher suspended sediment concentration events at all OBS locations which, together with the higher velocities, results in higher computed sediment fluxes (the range of the $y$ axis on the computed fluxes of Figure 10-b is the double than in previous plots). The B_E1 wave test presented an average of 7.5 short waves per wave group while the B_E2 wave test had an average of 3.6 short waves during each wave group. Due to the lower number of short waves within the wave group, there is also a reduction in the number of wave-wave and wavebackwash interactions within one wave group. The run-up under B_E2 condition is up to $5.7 \mathrm{~m}$, which is $29 \%$ more than under B_E1 conditions. B_E2 SSC peaks are mainly controlled by the processes around the shoreline, but some SSC events are measured at the most offshore OBS location (black line for $\mathrm{x}=-2.7 \mathrm{~m}$; at times equal to 19,48 and $79 \mathrm{~s}$ on Figure 10-b). Although the wave group and measured velocities have a $15.1 \mathrm{~s}$ period (as shown in Figures 6-d and 10-b), the SSC peaks present the more significant SSC events every 30-34 s. There are 3.6 short waves within each wave group, and therefore the short wave/wave group phase repeats itself every 2 wave groups, which corresponds to the $30 \mathrm{~s}$ period of the SSC major peaks (repeat frequency reported by Baldock et al. 2000).

The highest SSC peaks at shoreline locations are controlled by strong wave-backwash interactions (Figure 10-b at $\mathrm{t}=15,45$ and $74 \mathrm{~s}$; red and green lines for $\mathrm{x}=-0.5$ and $0.5 \mathrm{~m}$ respectively). The strong wave-backwash occurs when the receding backwash is more energetic than the incoming uprush, which results in a stationary bore that does not allow the run-up to advance and propagate along the shoreface (hydraulic jumps described by Broome and Komar 1979 and Butt and Russell 2005). Once the energy of the incoming wave is depleted in the bore, the remaining backwash energy prevails and moves the re-suspended sediment offshore with its natural negative velocity (offshore directed). The top panel in Figure 10-b shows a wave reaching the shoreline at the ADS ($1.7 \mathrm{~m}$ black line $\mathrm{t}=42 \mathrm{~s}$ ), its water surface elevation is comparable to the one measured under the previous wave $(t=36 \mathrm{~s})$. This second wave is measured at the location of $\mathrm{x}=0.4 \mathrm{~m}$ (red line) but there is no propagation up to $\mathrm{x}=1.86 \mathrm{~m}$ (green line) where the first wave produced a peak $(\mathrm{t}=38 \mathrm{~s})$ but the second wave produce a really small run-up $(t=44 \mathrm{~s})$. Simultaneously, the ADV deployed at $\mathrm{x}=-0.5 \mathrm{~m}$ (red line on second panel) shows a negative velocity at the arrival of this second wave (from $t=40$ and up to $t=50 \mathrm{~s}$ ). With the arrival of the second wave, the velocity measurement reduces its negative value (offshore) without reaching positive values (shoreward). The inability to reach positive velocities under such energetic wave conditions shows the necessary energetic exchange that halt the wave propagation (bore or hydraulic jump). 
The other peaks at shoreline positions $(\mathrm{t}=21,51$ and $81 \mathrm{~s})$ can be produced by the arrival of short waves bores in the trough of the wave group period or by advection. Its origin is uncertain due to the lack of wider measurement grid, but the most probable explanation is that advection from previous peak and local resuspension both play a role in the measured peaks at the consecutive OBS locations. The SSC peak measurement at $\mathrm{x}=-2.7$ (black line in the third panel at $\mathrm{t}=19,48$ and 79 s) is most likely due to advection. The sediment is suspended by the strong wave-backwash interaction at shoreline positions, and the resulting backwash advects the sediment to the measurement location at $\mathrm{x}=-2.7 \mathrm{~m}$. The reasoning for this conclusion is based on the time lag measured between the peaks at different locations and the measured velocities that fit with the advection process. In addition to the consistent advection time, the SSC peaks occur at the end of the trough and before the next arriving wave reaches the measurement location and, therefore, prior to the wave breaking at this point.

The maximal measured velocities for test B_E2 are the highest magnitudes for all the tests performed (Table 3). The positive velocities occur while there is sediment in suspension and produce the highest magnitude shoreward sediment flux. This shoreward sediment transport at the wave breaking in the trough of the wave group is responsible for berm formation. Negative sediment fluxes occur at the end of the backwash phase. The SSC that is suspended during the momentum energy exchange, which is due to a strong wave-backwash interaction, is finally offshore directed (17, 47 and $77 \mathrm{~s}$ on the lower panel of Figure 10-b) by the prevailing backwash velocity. The high negative velocities produce a substantial erosion in the surf and swash zone, with all suspended sediment being advected offshore. The high sediment transport rates, both shoreward and offshore, produce the biggest measured erosion along the surf and swash zone, the lack of trough behind the bar and the steeper beachface slope (1/6.9) measured during these experiments.

\subsection{Accretive conditions}

The Accretive condition comparison of the bathymetric measurement profiles is complex due to the fact that the Benchmark case for Accretive conditions (R_A1) shows no apparent sediment transport (Figure 7-f). Monochromatic and Combination conditions produce a berm formation, while Bichromatic conditions erode the first bar and produce a secondary bar closer to the shoreline at the breaking location.

Figure 11-a shows the mean of the ensemble average for Monochromatic Accretive conditions.

Water surface elevation, velocity and suspended sediment concentrations are controlled by the wave 
bore arrival, which breaks at a location of around $\mathrm{x}=-2 \mathrm{~m}$ (first breaking). The OBSs, which are located at $\mathrm{x}=-1$ and $0 \mathrm{~m}$ (red and green lines in the second panel), measure the advection of the stirred sediment at breaking. The time delay between both measured peaks corresponds to the advection time in accordance with the shoreward recorded velocities. The bigger SSC measurements are located around the shoreline despite the fact that the sediment has been stirred up at an offshore location and is advected up to this position. The shoreline location of the highest SSC events also imply the sediment pickup as the bore propagates onshore from the breakpoint.

The main difference between the Monochromatic Erosive and Accretive conditions is the breaking location and the lack of undertow under Accretive conditions, the combination of both effects will modify the sediment advection patterns. Under Accretive conditions the waves have their first breaking at $\mathrm{x}=-2 \mathrm{~m}$, while the main breaking under Erosive conditions occurred around $\mathrm{x}=-6.5 \mathrm{~m}$. The wave breaking closer to the shoreline (M_A) means that every run-up event is loaded with stirred sediment, thus producing a shoreward suspended sediment flux for every arriving wave (lower panel in Figure 11-a). This condition promotes berm formation while the shoreline has a slight advance. The negative mean velocities under Accretive conditions are negligible at the offshore location $(-0.02 \mathrm{~m} / \mathrm{s})$ and significantly lower for ADVs at $\mathrm{x}=-3.3$ and $-1 \mathrm{~m}(-0.10$ and -0.19 $\mathrm{m} / \mathrm{s}$ respectively) than the values previously measured under Erosive conditions, thus reducing the offshore drift of the suspended sediment.

Both Combination Accretive conditions, Figure 11-b and 11-c for C_A2 and C_A4 respectively, are controlled by the short waves breaking close to the shoreline (Figure 8-b and 8-c). The long free wave is also present at all hydrodynamic measurements with a lower energy content, causing a modulation of the short waves at shoreline positions. This effect can be seen on the spectral analysis but also on the ensemble averages, both velocity and SSC events at $\mathrm{x}=-1 \mathrm{~m}$ (red lines in second and third panels of Figure 11-b) are affected by the long wave component ( $f=0.034 \mathrm{~Hz}$ ) with a clear $30 \mathrm{~s}$ modulation of the measured parameters. The long wave modulation is neater for the C_A2 case because the number of short waves within the long wave period is 5.1, so both short wave and long wave peaks will be in phase at every long wave peak. For the C_A4 test, the number of short waves within the long waves is 2.6 , and the mismatch of both phases will increase the repetition time. This phase mismatch produces a fuzzier ensemble SSC average, increasing the standard deviation of the measured events in the ensemble. Waves start breaking around $\mathrm{x}=-3 \mathrm{~m}$ at both Combination conditions and maintain a high turbulence up to the shoreline (visual inspection from video images), which matches the maximum SSC peaks measured at both shoreline positions $(\mathrm{x}=-1$ and $0 \mathrm{~m})$. The waves perform a neat short run-up and run-down excursion free of wave- 
swash interactions. The highest run-ups are measured at the crest of the long wave. Both Combination conditions have a clear shoreward component in the computed suspended sediment flux at each bore arrival (fourth panel in Figures 11-b and c). Each bore arriving at the beach has sediment in suspension that contributes to the final measured berms.

The time series analysis of the B_A1 test shows an initial wave breaking between the measurements at $\mathrm{x}=-12$ and $-10 \mathrm{~m}$ (where the first bar is located) and a second breaking after $\mathrm{x}=-5 \mathrm{~m}$ where the second bar is formed along the Runs of this wave condition. Figure 12-a shows the ensemble average of B_A1. The water surface elevation ensemble (top panel) shows the arrival of broken bores up to the shoreline in groups controlled by the wave group period. The water surface energy on the PSD (top panel of Figure 8-d) presents a greater energy value for the long frequency, which is consistent with the wave group ( $29 \mathrm{~s}$ ), than for short targeted waves at shore line positions (green line at $\mathrm{x}=-2.2 \mathrm{~m}$ ). The length of the wave groups allows for several wave-swash interactions during the run-up and run-down at the swash zone. The wave group has limited influence on the velocity time series at the different measurement locations, while the SSC measurements seem to be affected more significantly by the wave group influence. Three high SSC events are measured during the period of each wave group (i.e. the central wave group covering the time span from $t=$ $30 \mathrm{~s}$ to $\mathrm{t}=60 \mathrm{~s}$ on the third panel of Figure 12-a). The three events include a wave bore arriving at the shoreline (at $\mathrm{t}=39 \mathrm{~s}$ ); and two weak wave-backwash interactions (at $\mathrm{t}=45$ and $51 \mathrm{~s}$ ) occurring when the waves arrive after the maximum run-up excursion, with the run-up being more energetic than the receding backwash. The three events have a positive velocity and the run-up reach upper positions in the emerged slope (as seen in the measured peak at the ADS located at $1.34 \mathrm{~m}$, green line in the upper panel of this figure 12-a). The weak wave-backwash interaction and the later runup event usually produce shoreward transport (Cáceres and Alsina 2012), which is also reported by the computed suspended sediment flux of the lower panel.

The mean of the ensemble average reflects accurately the behaviour of all wave conditions presented so far. The Bichromatic Accretive conditions are an exception to that rule and show significant differences between the ensemble average and the complete time series due to the phase shift between the short targeted waves and the wave group period. Figure 13-a reproduces the time series evolution under B_A1 condition over a $100 \mathrm{~s}$ interval and present SSC peaks which were masked by the ensemble average process on Figure 12-a. On the ensemble average the SSC events are mainly controlled by wave-backwash interactions, which are also present on Figure $13-\mathrm{a}(\mathrm{t}=$ $523,547,554,586$ or $611 \mathrm{~s}$ at OBS $\mathrm{x}=-1$ ). Moreover these events there are other events which were not properly represented on the ensemble as the wave breaking in the trough of the long wave 
$(t=498 \mathrm{~s}$, red line on Figure 13-a), or the SSC peaks measured at the most offshore OBS $(x=-3.32$ $\mathrm{m}$ at $\mathrm{t}=510,578$ and $584 \mathrm{~s}$, black line of third panel on Figure 13-a). This last group of SSC peaks are correlated with the consecutive high waves appearing within the rising of the wave group after the wave trough.

Figure 12-b shows the ensemble average for B_A2 wave condition. As seen on the Erosive conditions, the bichromatic Accretive condition that has a wave group period of $15 \mathrm{~s}$ is the case that presents bigger run-ups, velocities and SSC events. Figure 12-b also shows how the different hydrodynamic parameters at the surf and swash zones are controlled by the wave group period. The major SSC events measured during this condition are primarily produced by wave-backwash interactions $(\mathrm{t}=31,45,59,73$ and $87 \mathrm{~s}$ for both OBS at $\mathrm{x}=-1$ and $0 \mathrm{~m})$ and wave bores arriving in the trough of the long wave $(t=36,51,65$ and $80 \mathrm{~s}$ mainly at $\mathrm{x}=0 \mathrm{~m})$. Due to the phase change of the short waves and the wave group, which is considered in the next paragraph, the kind of interaction evolves in time and position causing large standard deviation values around the OBS measurements (red and green shaded areas on the third panel). The measured wave-backwash interactions evolve in time being weak at the beginning of the ensemble $(t=31,45$ and $59 \mathrm{~s})$ and strong at the end of the ensemble $(t=73$ and $87 \mathrm{~s})$.

Figure 13-b shows the water surface, velocity, SSC and computed suspended sediment fluxes along one complete Run of B_A2 tested condition. The longer pattern presented here, which has a repetition time of 120 seconds, is produced by the non integer number of short waves within each wave group. The wave group period is $15.15 \mathrm{~s}$ (upper panel of Figure 8-e) and contains 2.1 short waves $(7.1 \mathrm{~s})$. A second period of $13.3 \mathrm{~s}$ appears at the lower panel of Figure 8-e corresponding to the SSC events measured at the shoreline (magenta line at $\mathrm{x}=0 \mathrm{~m}$ ). Considering the second wave group period, which seems to control the SSC measured at the shoreline, 1.8 short waves are included in each wave group and, therefore, 9 wave groups are required to repeat the short wave/wave group phase. The 9 wave group repetition (120 s period) can be seen on Figure 13-b in all the recorded physical parameters. The velocity shows the $120 \mathrm{~s}$ modulation but it is more clearly presented in the water surface elevation of the ADS at $\mathrm{x}=1.3$ (green line upper panel of Figure 13b) which shows the pattern of the run-up events, or at the OBS readings at shoreline positions (red and green line on third panel). The computed suspended sediment fluxes (lower panel of Figure 13b) are also affected by the phase shift. The main change observed in the sediment fluxes along the $120 \mathrm{~s}$ repeating period affects the magnitude of the computed flux peaks. The maximum suspended sediment flux peaks are up to four times larger than the computed peaks when both periods are out of phase. 
Most SSC events for Monochromatic and Combination Accretive conditions are short waves breaking at the shoreline, which tend to produce shoreward transport. Bichromatic conditions, in addition to the short waves breaking in the trough of the long wave, are governed by weak wavebackwash interactions. Both driving SSC events, wave bore breaking at shoreline and weak wavebackwash interactions, tend to produce suspended sediment shoreward fluxes, and therefore they both tend to accrete the shoreline. Despite this expected Accretive process under both Bichromatic conditions, no significant Accretion is seen in the emerged beachface. 


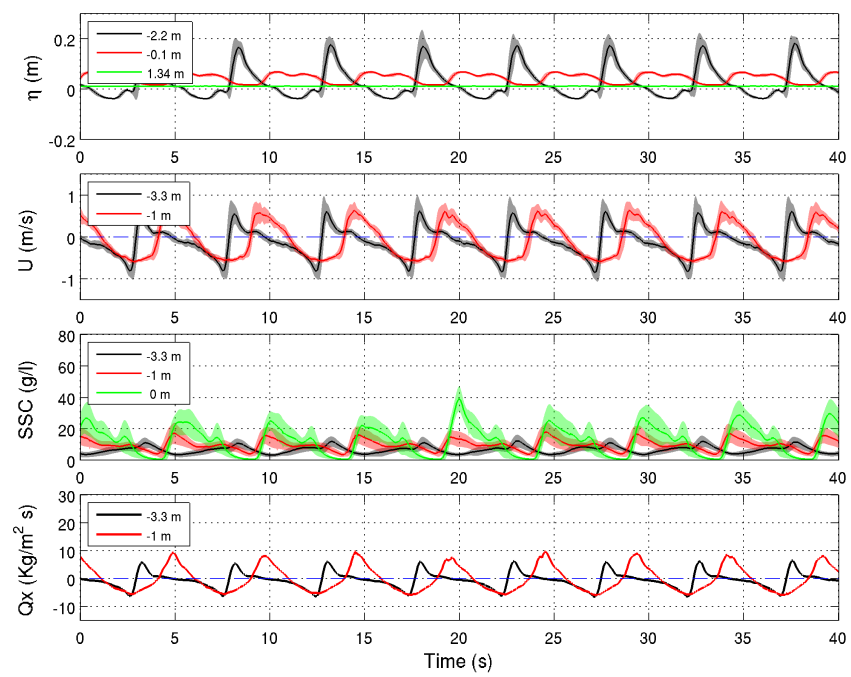

a)
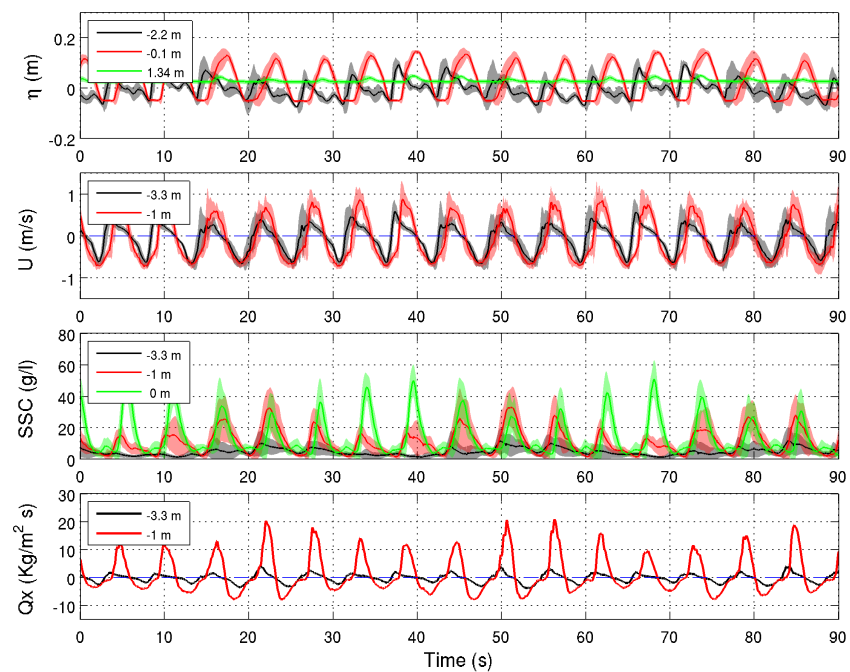

b)
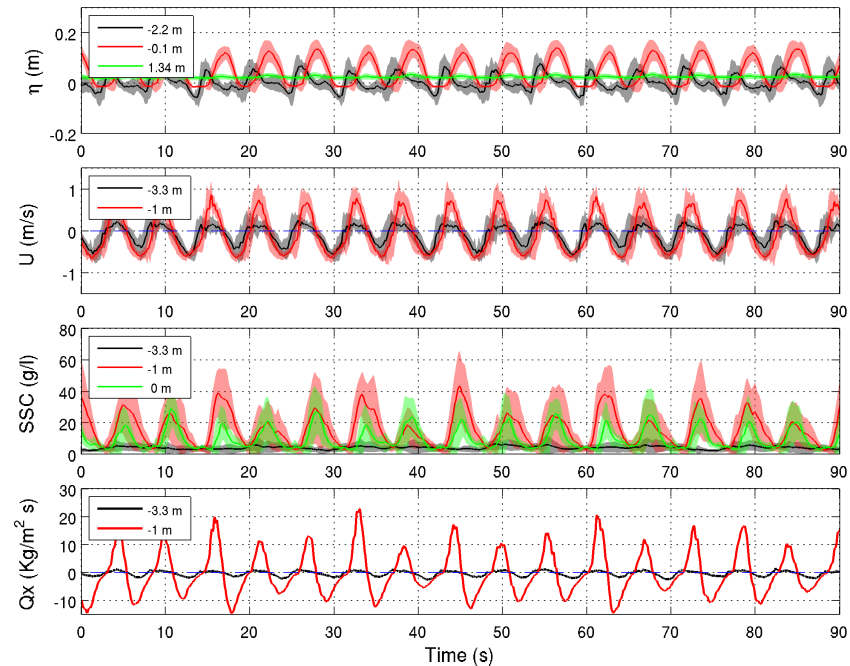

c)

Figure 11. Ensemble average for Accretive wave conditions a) for M_A, b) for C_A2 and c) for C_A4. Solid line for the mean of the ensemble during the time series while the lightly shaded area reports the standard deviation of the mean. 

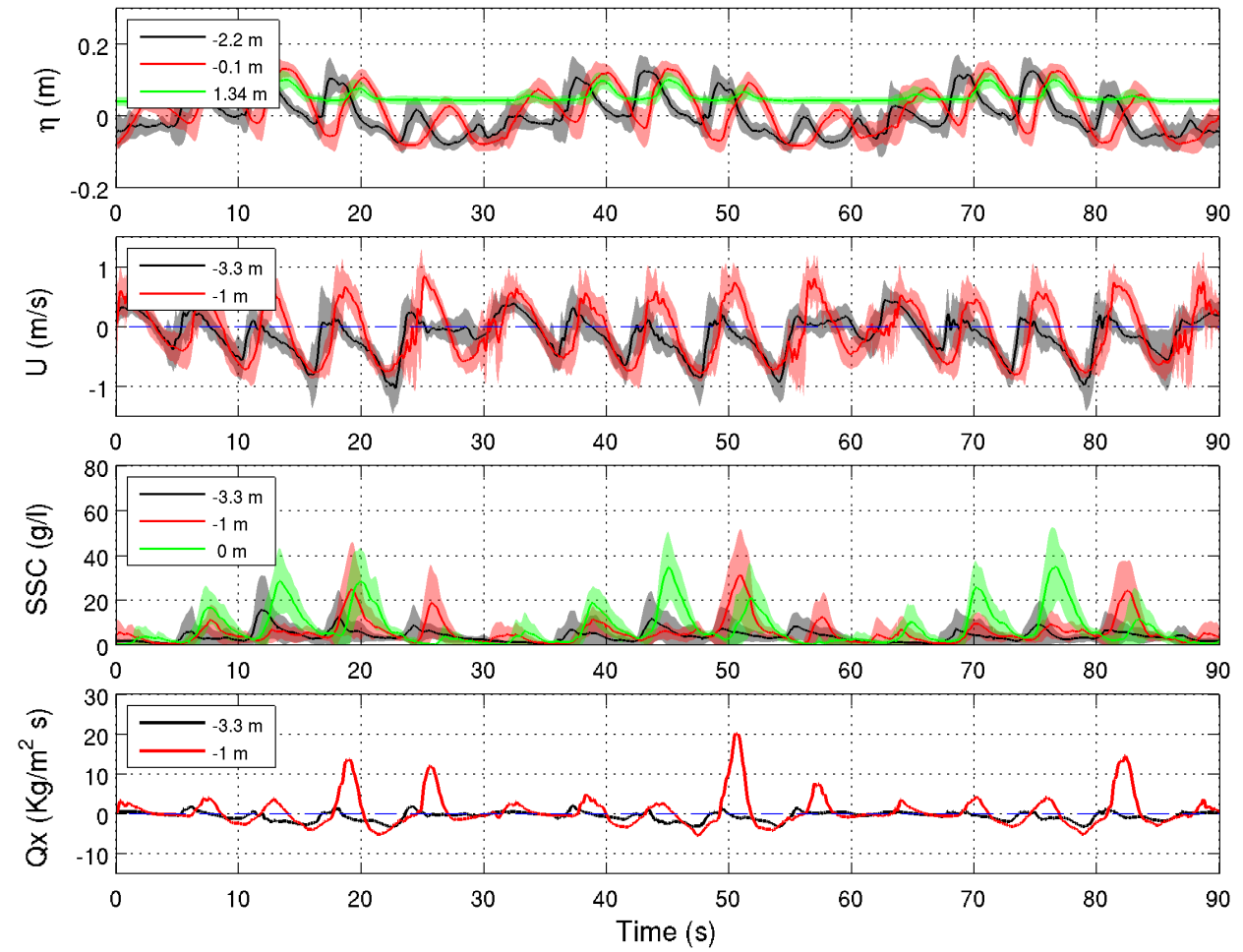

a)
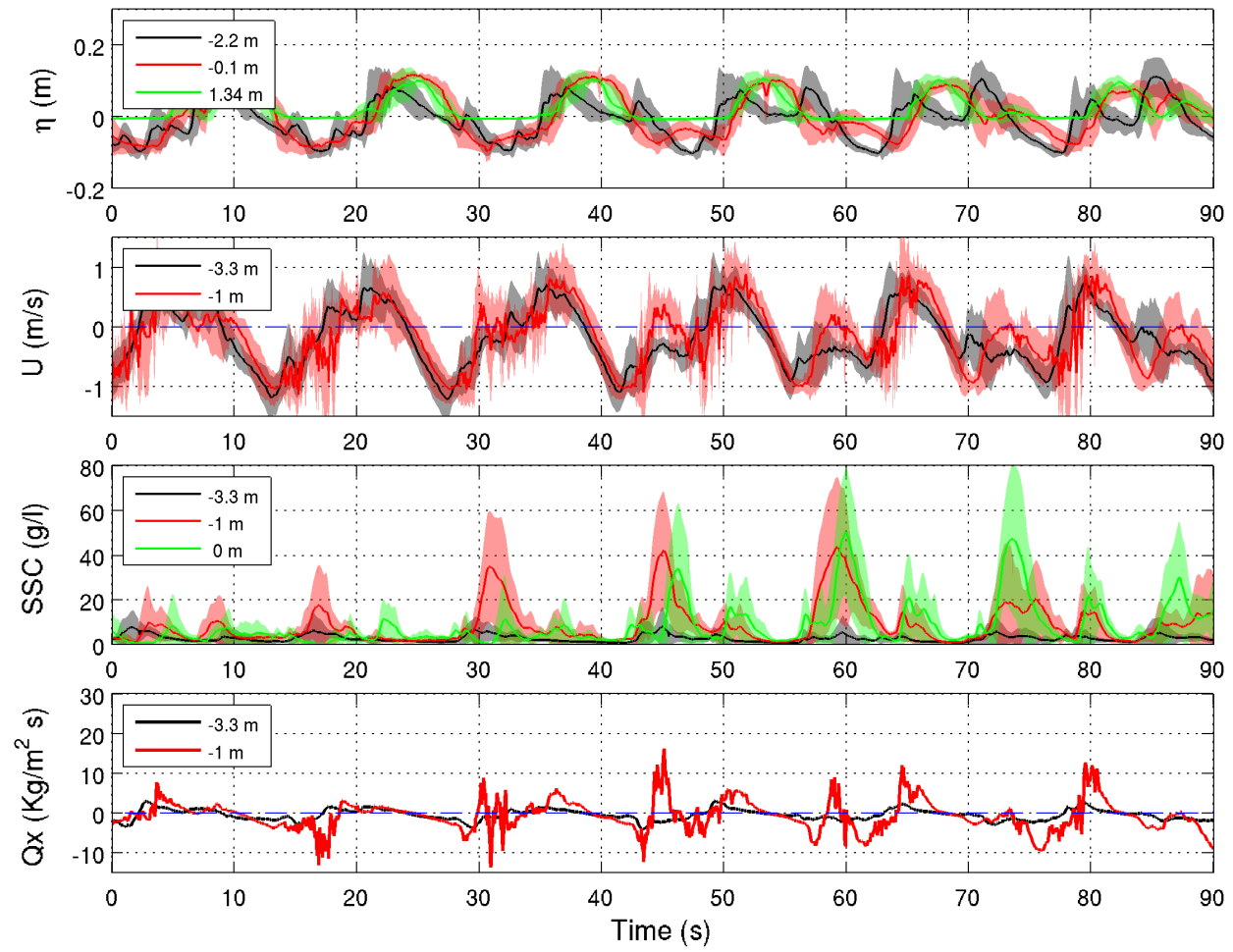

b)

Figure 12. Ensemble average for Accretive wave conditions a) for B_A1 and c) for B_A2. Solid line for the mean of the ensemble during the time series while the lightly shaded area reports the standard deviation of the mean. 

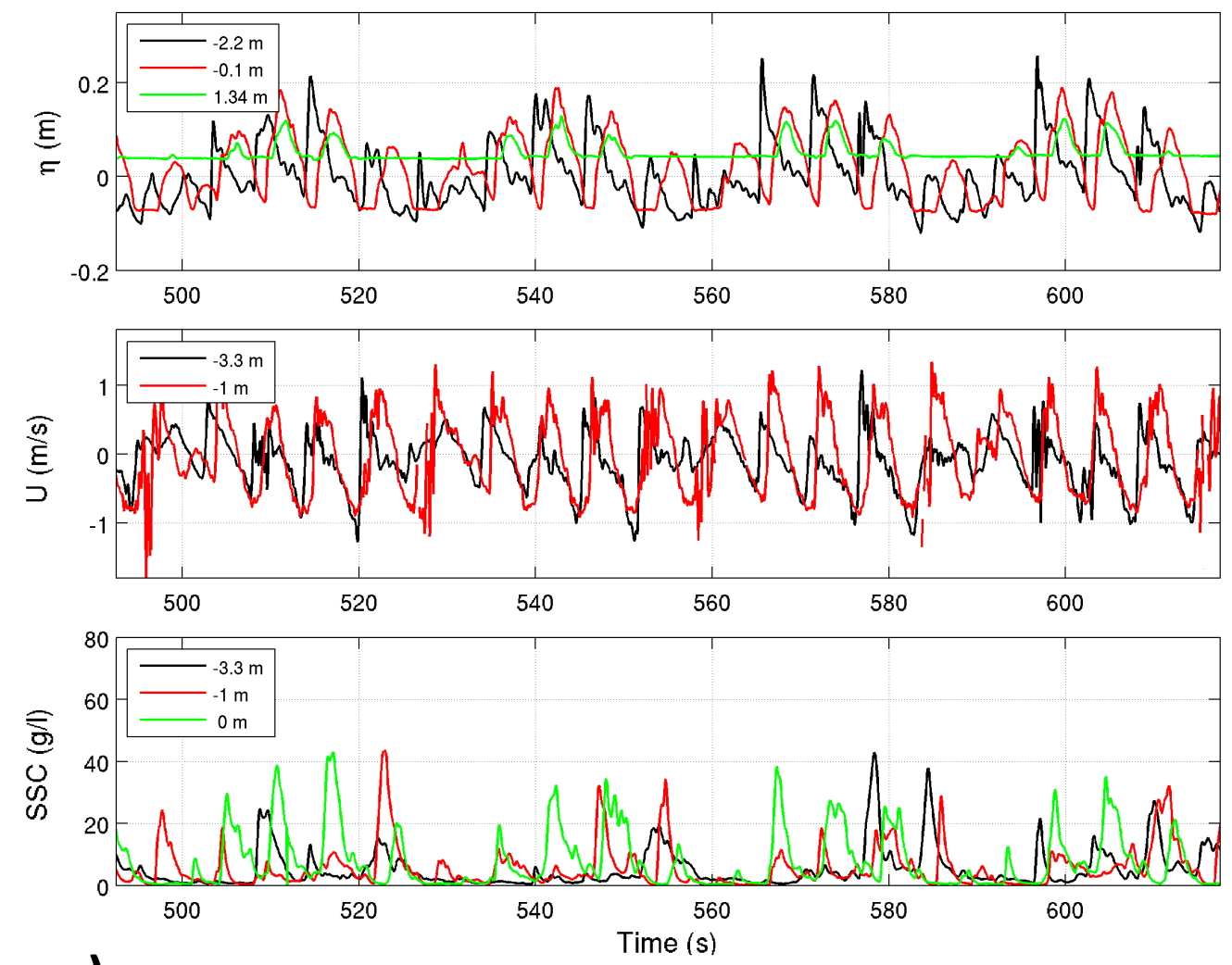

a)
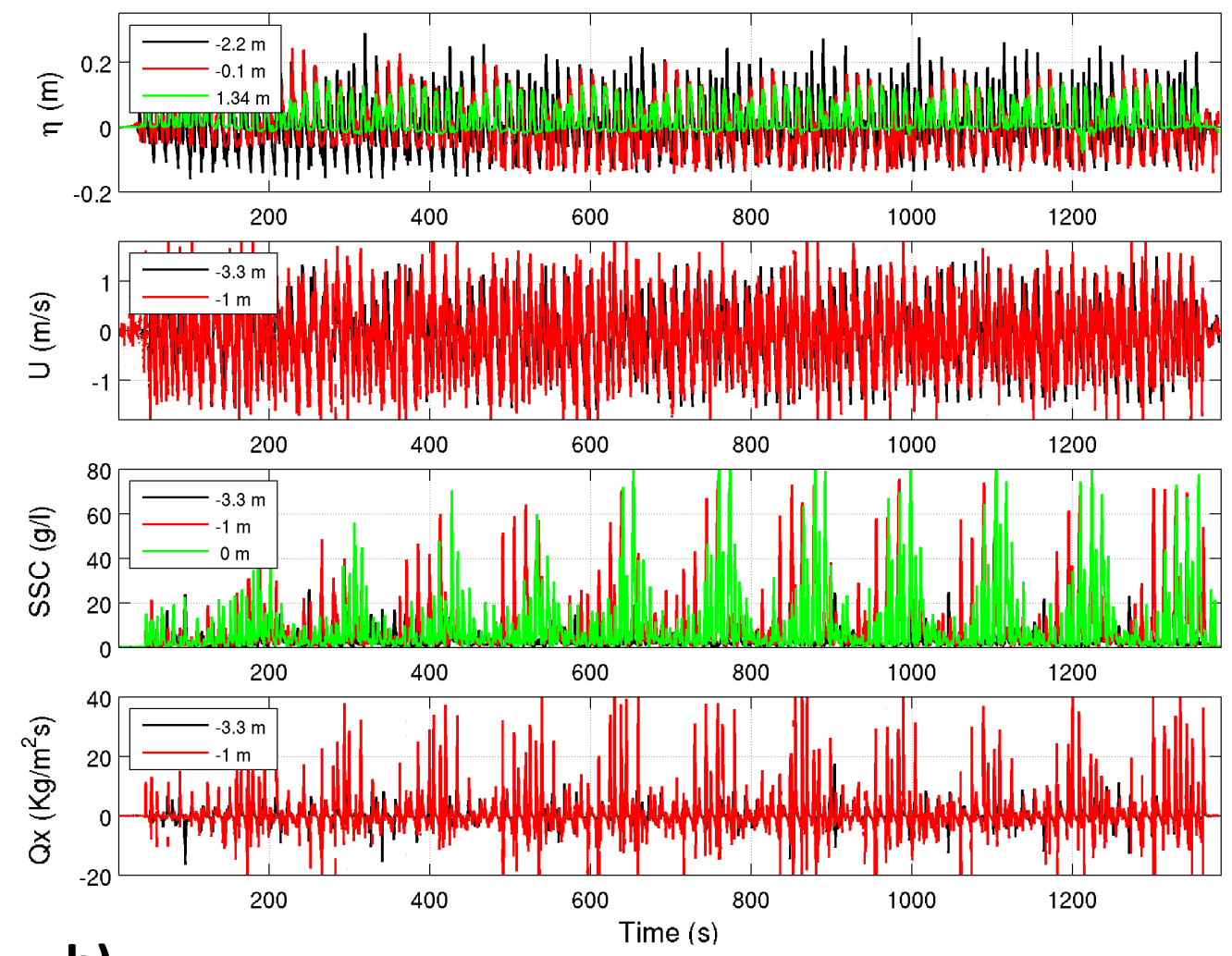

b)

Figure 13. Wave height, velocity and SSC measurements time series a) for B_A1 and b) for B_A2 wave conditions. 


\subsection{Berm formation}

Berm formation does not seem to be directly correlated with the measured parameters (wave heights, presence or absence of a long wave, run-up excursion or velocity values). Under erosive wave conditions, there is berm formation for tests C_E4, B_E1 and B_E2 with berm heights of $0.07,0.04$ and $0.10 \mathrm{~m}$ respectively and volumes of $0.42,0.21$ and $0.69 \mathrm{~m}^{3}$ respectively. On the other hand, the Accretive conditions present berm formation under M_A, C_A2 and C_A4, with maximum berm heights of $0.12,0.17$ and $0.19 \mathrm{~m}$ respectively and berm volumes of $0.63,0.93$ and $1.16 \mathrm{~m}^{3}$ respectively. The run-up excursion correlates with the berm location (Tables 4 and 6 ). The further the run-up is able to reach, the further the berm location will be if the berm is formed during this wave condition. The most distant Berms locations are found for B_E2 at $\mathrm{x}=5.2 \mathrm{~m}$ under Erosive conditions, and for $\mathrm{C}_{-} \mathrm{A} 2$ and $\mathrm{C}_{-} \mathrm{A} 4 \mathrm{at} \mathrm{x}=1.7 \mathrm{~m}$ for Accretive conditions.

The berm height and volume can be correlated to the mechanisms that produce the suspended sediment peak events under each studied case. The wave conditions that present berm formation must have significant SSC events during or before pure swash events (pure events which can be either short waves or short waves in the trough of a long wave). Although SSC events are controlled by the arrival of short waves, M_E condition is a case that does not promote berm formation, but this is due to the fact that most of the short waves arriving under this tested condition break far away from the shoreline. The measurements close to the shoreline report small positive velocity values and low sediment in suspension, which end up producing lower computed sediment fluxes. All wave conditions that develop a berm present significant SSC events due to short waves breaking at the shoreline accompanied by significant shoreward velocities.

The wave conditions that produce bigger and higher berm formations are B_E2, C_A4 and C_A2. B_E2 condition is the case that produces the most substantial berm (in height, volume and distance) when comparing the Erosive wave conditions. Berm formation under B_E2 conditions is due to the timing of SSC events prior to the highest positive velocities that are able to move the suspended sediment particles up to the furthest point within the emerged area. Figure 10-b shows two significant SSC events at each wave group. Before the trough of the long wave (i.e. $t=15,45$ or 74 s) there is a wave arriving that produces a strong wave-backwash interaction, thus producing a SSC event at $\mathrm{x}=-0.5 \mathrm{~m}$ (red line of third panel). Strong wave-backwash interactions are expected to suspend the sediment that was already being advected down the beach face by the previous backwash. This event suspends a significant amount of sediment which is partially advected to offshore positions (OBS at $\mathrm{x}=-2.7 \mathrm{~m}$ ) but also will be shoreward transported by the next wave 
arriving in the trough of the long wave. This arriving wave helps to resuspend more sediment, but also advects the previously suspended sediment shoreward. The computed sediment fluxes during this condition (lower panel on Figure 10-b) show clear positive peaks every $30 \mathrm{~s}(\mathrm{t}=21,51$ and 81 s).

There are no big differences between $C_{-}$A4 and C_A2, as can be seen on Figure 11 and the data already discussed regarding berm formations. The measured water surface elevation and velocities close to the shoreline are similar, with the mean ensemble presenting slightly higher SSC events for C_A4. The berm volume differences are lower than $10 \%$ at both conditions and the mechanism that produces both berms is the wave arrival and breaking at shoreline locations, as can be seen on Figures 11-b and c. C_A4 is the case that produces the biggest berm under Accretive conditions.

When comparing C_A4 and B_A2, the data show that both conditions have similar measured shoreward velocity peaks (Table 5) at shoreline locations, high suspended sediment concentration values around the shoreline, close water surface elevations and the same wave group period. But despite this, the berm formation is completely different. While C_A4 creates the highest berm, B_A2 do not present any berm formation. Under B_A2 conditions, some of the SSC events are controlled by short waves arriving on the trough of the wave group $(\mathrm{t}=35,51$ and $65 \mathrm{~s})$, but the most important SSC peaks are produced by weak wave-backwash interactions $(t=31,45$ and $59 \mathrm{~s}$ at Figure 12-b). Weak wave-backwash interactions, despite being accretive occur when the water surface measured at the shoreward location has already reached its maximum height (green line presenting run-up elevation at $\mathrm{x}=1.34 \mathrm{~m}$ ). The highest SSC peaks are therefore linked to events that occur once the run-up has reached its peak, therefore leading to limited shoreward sediment transport. Additionally, under B_A2 conditions the generation of longer period harmonics than the wave group period leads to the appearance of short accretive waves in the trough of the wave group every $120 \mathrm{~s}$, which further reduces the berm building capacity of these conditions.

\section{Conclusions}

A new, more in-depth data analysis of the SUSCO (Swash zone response Under grouping Storm COnditions) experiments is presented in this paper. The analysis focuses on the study of the wave spectra and time series of the measured physical parameters (water surface elevation, velocity and suspended sediment concentrations). This study aims to improve the knowledge of the role played by the driving terms that control the suspended sediment transport regime under different wave 
conditions, including Erosive and Accretive conditions. In order to study the role of long waves: Monochromatic conditions, small amplitude long waves (Combination) and fully Bichromatic conditions have been studied, focusing our efforts on understanding the different Suspended Sediment Concentration events generated under the tested conditions.

The data suggests that the presence of long waves significantly increase the wave breaking area, thereby widening the region of sediment transport. The long waves control the number of wavebackwash interactions along the swash-zone, and type of such interaction by regulating the location and timing at which such interactions occur. The type of wave-backwash interaction, its location and timing relative to the previous or next suspended sediment event, determines the sediment transport pattern to erode the shoreline or promote a shoreward sediment transport. The wave group and short wave period ratio also plays a significant role in the suspended sediment fluxes through the generation of harmonics with longer periods than the wave group.

The time evolution of morphological features is affected by the length of the breaking area. The wave conditions with wider breaking areas, random and bichromatic waves, need longer time periods to reach a stationary position. The bar morphological features developed under Bichromatic Erosive conditions (location, height and volume) are the ones that are closest to the profile measured under Random conditions, which is considered as benchmark. Random Accretive conditions do not produce any change on the measured profiles, while the other tested Accretive conditions (Monochromatic, Combination and Bichromatic) generate sediment accretion by means of berm formation, by eroding the main bar with shoreward sediment transport or by creating a secondary bar closer to the shoreline.

Monochromatic waves and Combination waves are mainly controlled by the short waves breaking at the shoreline, and by short waves in the trough of the long wave, which tend to slightly erode the shoreline due to significant undertow under Erosive conditions. However, Accretive conditions lack significant undertow velocities, thus producing a slight accretion of the shoreline controlled by the shoreward transport of short waves breaking at shoreline positions. The shoreline accretion under this condition does not promote shoreline advance, at least at the initial stages of the experiments performed, but develops berm formations which are consistent with the analyzed hydrodynamic parameters.

Bichromatic conditions result in a more complex behaviour. The number of short waves within the wave group, controlled by the short and long wave ratio, govern the number of interactions and 
hence the energy of erosion and accretion under the different tested conditions. A small number of interactions tends to result in the arrival to the shoreline of bigger waves, higher velocities and therefore bigger sediment transports. All bichromatic conditions, both Erosive and Accretive, have a clear influence on SSC events in the swash induced by the wave group periods.

The presence of short waves breaking at the shoreline is necessary for berm formation. These waves produce long run-ups that are able to produce a berm. On the other hand, if wave-swash interactions are present (strong wave-backwash is erosive and weak wave-backwash is weakly accretive), the berm will form if the described interactions are followed by short waves progressing in a net runup. The presence of wave-backwash interactions increases sediment stirring into suspension, but the waves breaking at the shoreline will be the ones that produce a more efficient shoreward sediment transport.

\section{Acknowledgments}

This work has been supported by European Community's 6th Framework Programme through the grant to the budget of the Integrating Activity HYDRALAB III (Contract no. 022441). The first author also acknowledge the economical funding and support received from the MINECO and FEDER who founded the Plan-Wave project (ref. CTM2013-45141-R), and the Secretaria d'Universitats i Recerca del Dpt. d'Economia i Coneixement de la Generalitat de Catalunya (Ref 2014SGR1253).

\section{Bibliography}

Aagaard, T., Hughes, M.G., Møller-Sørensen, R. and Andersen, S., 2006. Hydrodynamics and sediment fluxes across an onshore migrating intertidal bar. Journal of Coastal Research, Vol. 22 (2): 247-259.

Alsina, J.M., Falchetti, S. and Baldock, T.E., 2009. Measurements and modelling of the advection of suspended sediment in the swash zone by solitary waves. Coastal Engineering, Vol. 56: 621-631.

Alsina, J.M. and Cáceres, I., 2011. Sediment suspension events in the inner surf and swash zone. Measurements in large-scale and high-energy wave conditions. Coastal Engineering, 58(8): 657-670.

Alsina, J.M., Cáceres, I., Brocchini, M. and Baldock, T., 2012. An experimental study on sediment transport and bed evolution under different swash zone morphological conditions. Coastal Engineering, Vol. 68, pp. 31-43.

Bagnold, R.A., 1940. Beach formation by waves: some model experiments in a wave tank. Journal of Institution of Civil Engineers 15, 27-52. 
Bagnold, R.A., 1966. An approach to the sediment transport problem from general physics. U.S. Geological Survey Professional Paper. 422-I, 37 p.

Baldock, T.E., Holmes, P., Horn, D.P., 1997. Low frequency swash motion induced by wave grouping. Coastal Engineering 32, 197-222.

Baldock, T. E., Huntley, D. A., Bird, P. A. D., O'Hare, T. and Bullock, G. N., 2000. Breakpointgenerated surf beat induced by bichromatic wave groups. Coastal Engineering, 39: 213-242.

Baldock, T.E. and Nielsen, P., 2010. Discussion of "Effect of Seepage-Induced Nonhydrostatic Pressure Distribution on Bed-load Transport and Bed Morphodynamics" by Simona Francalanci, Gary Parker, and Luca Solari. Journal of Hydraulic Engineering, Vol. 136, 7779.

Baldock, T.E., Alsina, J.M., Cáceres, I., Vicinanza, D., Contestabile, P., Power, H and SánchezArcilla, A., 2011. Large-scale experiments on beach profile evolution and surf and swash zone sediment transport induced by long waves, wave groups and random waves. Coastal Engineering, 58(2): 214-227.

Bakhtyar, R., Barry, D.A., Li, L., Jeng, D.S. and Yeganeh-Bakhtiary, A., 2009. Modeling sediment transport in the swash zone: A review. Ocean Engineering, Vol. 36: 767-783.

Blenkinsopp, C.E., Turner, I.L., Masselink, G. and Russell, P.E., 2011. Swash zone sediment fluxes: field observations. Coastal Engineering, Vol. 58 (1): 28-44.

Brocchini, M. and Baldock, T.E., 2008. Recent advances in modeling swash zone dynamics: influence of surf-swash interaction on nearshore hydrodynamics and morphodynamics. Reviews of Geophysics 46, RG3003.

Broome, R. and Komar, P.D., 1979. Undular hydraulic jumps and the formation of backwash ripples on beaches. Sedimentology, 26, 543- 559.

Butt, T. and Russell, P.E., 1999. Suspended sediment transport mechanisms in high-energy swash. Marine Geology, Vol. 161: 361-375.

Butt, T. and Russell, P.E., 2000. Hydrodynamics and Cross-Shore Sediment Transport in the Swashzone of Natural Beaches: A Review. Journal of Coastal Research, Vol. 16-2: 255-268.

Butt, T. and Russell, P.E., 2005. Observations of Hydraulic Jumps in High-Energy Swash. Journal of Coastal Research, Vol. 21-6: 1219-1227.

Cáceres, I. and Alsina, J.M., 2012. A detailed, event-by-event analysis of suspended sediment concentration in the swash zone. Continental Shelf Research, Vol. 41, 61-76.

Dean, R, G., 1973. Heuristic models of sand transport in the surf zone. Proc. Conf. on Engrg. Dynamics in the Surf Zone, Institution of Engineers, 208-2

Dean, R.G., 1985. Physical modelling of littoral processes. In: Dalrymple (Ed.), Physical Modelling in Coastal Engineering. Balkema, Rotterdam.

Downing, J.P. and Beach, R.A., 1989. Laboratory Apparatus for Calibrating Optical Suspended Solids Sensors. Marine Geology, Vol. 86, 243-249.

Elfrink, B. and Baldock, T., 2002. Hydrodynamics and sediment transport in the swash zone: a review and perspectives. Coastal Engineering, Vol. 45, 149-167.

Erikson, L., Larson, M. and Hanson, H., 2005. Prediction of swash motion and run-up including the effects of swash interaction. Coastal Engineering, Vol. 52, 285-302.

Goring, D.G. and Nikora, V.I., 2002. Despiking acoustic doppler velocimeter data. Journal of Hydraulic Engineering, 128(1): 117-126.

Hallermeier, J.R., 1981. A Profile Zonation for Seasonal Sand Beaches from Wave Climate. Coastal Engineering, Vol. 4, 253-277.

Hine, A.C., 1979. Mechanics of berm development and resulting beach growth along a barrier spit complex. Sedimentology 26, 333-351.

Holland, K.T. and Pulleo, J.A., 2001. Variable swash motions associated with foreshore profile change. Journal of Geophysical Research, Vol. 106 (C3), 4613-4623.

Horn, D.P. and Mason, T., 1994. Swash zone sediment transport modes. Marine Geology, Vol. 120: 309-325. 
Houser, C. and Barrett, G., 2010. Divergent behavior of the swash zone in response to different foreshore slopes and nearshore states. Marine Geology, Vol. 271, 106-118.

Hughes, M.G., Masselink, G. and Brander, G., 1997. Flow velocity and sediment transport in the swash zone of a steep beach. Marine Geology,138: 91-103.

Hughes, M.G. and Baldock, T.E., 2004. Eulerian flow velocities in the swash zone: field data and model predictions. Journal of Geophysical Research, Vol. 109 (C08009): 1-11.

Hughes, M.G., Moseley, A.S., 2007. Hydrokinematic regions within the swash zone. Continental Shelf Research, Vol. 27: 2000-2013.

Jackson, N.L., Masselink, G. and Nordstrom, K.F., 2004. The role of bore collapse and local shear stresses on the spatial distribution of sediment load in the uprush of an intermediate-state beach. Marine Geology, Vol. 203 (1-2): 109-118.

Jensen, S.G., Aagaard, T., Baldock, T.E., Kroon, A. and Hughes, M., 2009. Berm formation and dynamics on a gently sloping beach; the effect of water level and swash overtopping. Earth Surface Processes and Landforms 34: 1533-1546.

Kemp, P.H., 1975. Wave asymmetry in the nearshore zone and breaker area In: Hails, J., Carr, A. (Eds.), Nearshore sediment dynamics and sedimentation. Wiley-Interscience, New-York, pp. 47-67.

Mariño-Tapia, I.J., Russell, P.E., O’Hare, T.J., Davidson, M.A. and Huntley, D.A., 2007. Crossshore sediment transport on natural beaches and its relation to sandbar migration patterns: 1 . Field observations and derivation of a transport parameterization. Journal of the Geophysical Research, Vol. 112 (C3, C03001), 1-15.

Masselink, G. and Puleo, J.A., 2006. Swash-zone morphodynamics. Continental Shelf Research, Vol. 26: 661-680.

Masselink, G., Russell, P., Turner, I., Blenkinsopp, C., 2009. Net sediment transport and morphological change in the swash zone of a high-energy sandy beach from swash event to tidal cycle time scales. Marine Geology, Vol. 267: 18-35.

Osborne, P.D. and Rooker, G.A., 1999. Sand Re-Suspension Events in a High Energy Infragravity Swash Zone. Journal of Coastal Research, 15: 74-86.

Pedrozo-Acuna, A., Ruiz de Alegria-Arzaburu, A., Torres-Freyermuth, A., Mendoza, E., Silva, R., 2011. Laboratory investigation of pressure gradients induced by plunging breakers. Coastal Engineering, Vol. 58, 722-738.

Puleo, J.A., Beach, R., Holman, R. and Allen, J., 2000. Swash zone sediment suspension and transport and the importance of bore-generated turbulence. Journal of Geophysical Research 17021-17044.

Roelvink, J.A. and Stive, M.J.F., 1989. Bar-generating cross-shore flow mechanisms on a beach. Journal of Geophysical Research, Vol. 94: 4785-4800.

Turner, I.L. and Nielsen, P., 1997. Rapid water table fluctuations within the beach face: implications for swash zone sediment mobility?. Coastal Engineering, Vol. 32, 45-59.

Vicinanza, D., Contestabile, P., Power, H., Alsina, J., Cáceres, I. (2009). Swash zone response Under grouping Storm Con- ditions (SUSCO). Internal Report EC contract no. 022441 (RII3), HYIII-WAVELAB-6, Canal d'Investigació i Experimentació Marítima (CIEM).

Weir, F.M., Hughes, M.G., Baldock, T.E., 2006. Beach face and berm morpho-dynamics fronting a coastal lagoon. Geomorphology 82: 331-346.

Zhu, F. and Dodd, N., 2013. Net beach change in the swash zone: A numerical investigation. Advances in Water Resources, Vol. 53: 12-22. 